
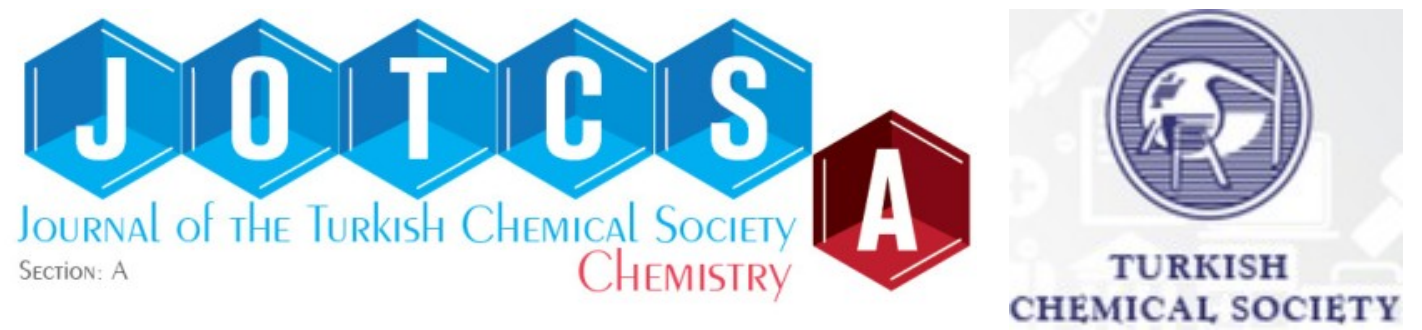

\title{
Extractive Desulfurization Using Piperidinium Based Ionic Liquids with Lewis Acids
}

\author{
Assim A. Sabah ${ }^{1 *}$ (D) \\ ${ }^{1}$ Department of Science, College of Basic Education, University of Mosul, Mosul, Iraq
}

\begin{abstract}
This work includes the preparation of ionic liquid 1,4-dimethylpiperidinium iodide [MMPip]I and its salts with ferric chloride as Lewis acid in different molar proportions [MMPip]I/ $\mathrm{nFeCl}_{3}(n=1,2,3)$. The prepared compounds were diagnosed by spectroscopic and physical methods such as ${ }^{1} \mathrm{H}-\mathrm{NMR}$, FT-IR, elemental analysis ( $\mathrm{CHN}$ ) and other techniques. The thermal stability of these compounds was studied to use in the extractive desulfurization process (EDS). The efficiency of these compounds in removing sulfur compounds from the petroleum model was examined using dibenzothiophene (DBT) with a concentration of $1000 \mathrm{ppm}$ dissolved in the solvent of normal hexane. The results showed that the compounds used had an acceptable efficiency of up to $30 \%$ despite using medium amounts of the extracted agent relative to the oil model; these compounds have a promising future in extractive sulfur removal processes.

Keywords: Piperidine ionic liquids, desulfurization, thermal study, lewis acid.
\end{abstract}

Submitted: July 07, 2021. Accepted: September 20, 2021.

Cite this: Sabah A. Extractive Desulfurization Using Piperidinium Based Ionic Liquids with Lewis Acids. JOTCSA. 2021;8(4):1057-88.

DOI: https://doi.org/10.18596/jotcsa.963930.

*Corresponding author. E-mail: assimsabah@uomosul.edu.iq.

\section{INTRODUCTION}

Desulfurization is one of the chemical processes used to remove sulfur from raw materials in industry or final products. These processes are critical because they provide a large portion of the sulfur used in other fields and other sulfur-free materials to reduce toxic and polluting emissions to the environment, such as SOx emissions that cause acid rain (1-3). The fuel refining process necessarily requires the removal of sulfur from the oil hardships. The Environmental Protection Agency has imposed global restrictions on the specifications of the fuels used in transportation (EPA)(4). The optimum allowable sulfur content in diesel and gasoline is $15-30 \mathrm{ppm}$, which was previously 500 $\mathrm{ppm}$ in most countries, and is now being reduced to $10 \mathrm{ppm}$ (5). Thus, one of the critical processes in oil refineries is the removal of sulfur from oil. The price of oil production is determined by the sulfur content, which influences the price of crude oil and processing costs $(1,6-8)$.
Ionic liquids (ILs) with a high distribution coefficient for sulfur compounds, a low cross solubility for hydrocarbons, a low viscosity, and a fast separation phase after mixing and extraction are ideal. Unfortunately, natural ionic fluids perform less efficiently in liquid-liquid extraction for typical sulfur compounds such as dibenzothiophene (DBT). However, ionic liquids have a high distribution coefficient. In mixtures, the distribution coefficient is somewhat low; in other words, liquids are not ideal solvents for extraction desulfurization, especially with heavy oil, and the (EDS) process efficiency is lower. Because oxidizing sulfur compounds have a much higher distribution coefficient, the efficiency of the ionic liquid extraction process increases if organic sulfur compounds have previously been oxidized to sulfoxides and sulfonates (9-11).

Desulfurization by extracting fuel with ionic liquids instead of conventional organic solvents is an exciting alternative to extremely clean diesel oils. The use of different ionic liquids have been investigated within (EDS) (cations such as 
imidazolium, pyridinium, quinolinium, and pyrrolidinium, anions such as alkyl sulfate, alkyl phosphate, halogens, ethanoate, and thiocyanate), the treatment carried with (DBT) dissolved in dodecane as a model fuel. The results showed that the extraction efficiency of the cationic ions is in the following order: methylpyridinium $\geq$ pyridinium $\approx$ imidazolium $\approx$ pyrrolidinium. Methylpyridinium cation showed the highest sulfur removal, up to $(80 \%)$ per batch $(12-16)$.

In practical experiments with the (EDS) process, it was found that ionic liquids containing Lewis acids such as $\mathrm{FeCl}_{3}, \mathrm{AlCl}_{3}$ and $\mathrm{CuCl}$ gave promising good results for the selective extraction process for aromatic sulfur compounds even when used in thermal conditions of up to $70{ }^{\circ} \mathrm{C}$ due to their solid presence $(17,18)$. In the (EDS) process, many ionic liquids mixed with Lewis acids were tested in different molar ratios, for example, the mixture between the ionic liquid (1-n-butyl-3-methyl imidazolium [BMIM] Cl ) and with aluminium chloride $\mathrm{AlCl}_{3}$ as Lewis acid in molar ratios [BMIM]Cl: $\mathrm{AlCl}_{3}$ (0.35:0.65) where the bilayer system was formed with the petroleum model at room temperature. It was also tested in the (EDS) process of real diesel. In the extraction process, the ionic liquids containing Lewis acids showed higher efficiency than their counterparts, non-containing Lewis acids (18, 19). Also, ionic liquids containing $\mathrm{ZnCl}_{2}$ were tested in the oxidative desulfurization process (ODS), [BMIM]Cl / $\mathrm{nZnCl} 2(\mathrm{n}=1,2,3)$, using the fuel model with concentrations of $500 \mathrm{ppm}$ and $1000 \mathrm{ppm}$ of (DBT). The results showed that the desulfurization efficiency decreases with the increase in the percentage of $\mathrm{ZnCl}_{2}$. These may be attributed to the strong binding of zinc chloride with the cation in ionic liquid; and its lack of participation in the desulfurization process (20). On the contrary, we notice the increase in extraction efficiency when using $\mathrm{FeCl}_{3}$ when increasing the ratio of ferric chloride to ionic liquid $\mathrm{nFeCl}_{3} /[\mathrm{BMIM}] \mathrm{Cl}(\mathrm{n}=1,2,3)$, which is due to the increase in acidity and the closer association of aromatic sulfur compounds with ionic liquids of higher ferric chloride $(15,18)$. The use of ionic liquid alone or Lewis acid alone did not show high efficiency in the (EDS) process. However, when using the mixing technique between them, the efficiency was higher. Therefore, the process of mixing them is beneficial, as an ionic liquid containing $\mathrm{FeCl}_{3}$ showed higher efficiency when compared with their counterparts containing $\mathrm{AlCl}_{3}$ or $\mathrm{CuCl}$ under the same experimental conditions (15, 21).

\section{MATERIALS AND METHODS}

All chemicals are of high purity and from certified international companies and used without any additional treatment.

\section{Preparation of ionic liquids systems}

The ionic liquids (molten salts) were prepared as mentioned in the literature (22-26), the ionic liquid 1,4-dimethylpiperidinium iodide [MMPip]I was prepared through the reaction of 4-methylpiperidine dissolved in absolute ethanol with the gradual addition of methyl iodide with continuous stirring for two hours with cooling, the reaction is exothermic. At the end of the reaction, evaporation followed by a rotary evaporator at $80{ }^{\circ} \mathrm{C}$ concentrated the solution and removed the remaining solvent. After that, the ionic liquid [MMPip]I reacted with $\mathrm{FeCl}_{3}$ in different molar proportions through mixing them with reflex for 4 hours and disposing of the used solvent (absolute ethanol) by rotary evaporator for 4 hours. Scheme 1 shows the preparation of the ionic liquids systems.<smiles>CC1CCNCC1</smiles>

4-methylpiperidine<smiles>CC1C[CH-][NH+](C)CC1</smiles>

[MMPip]I

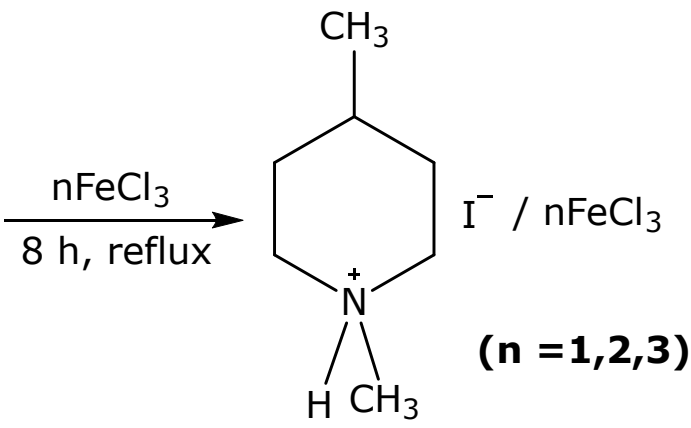

[MMPip]I/ $\mathbf{n F e C l} 3$

Scheme 1: Preparation of ILs systems.

\section{Extractive desulfurization using ILs Systems}

$1000 \mathrm{ppm}$ of sulfur content has been prepared by dissolving (DBT) in $n$-hexane (as model oil). In the process (EDS), the optimum conditions were determined by treating the prepared ionic liquid systems to several conditions of temperature, time and concentration of the extracted material. Conical flask $100 \mathrm{~mL}$ used in a shaker by adding $10 \mathrm{~mL}$ of the (DBT) model oil with a specified concentration of ionic liquid dissolved in $5 \mathrm{~mL}$ DMSO, 211DS Shaking Incubator used to control the operating conditions of the experiment. Analyzing the results of sulfur 
removal ratio was done by using absorption to create a standard calibration curve and determine the wavelength $\left(\lambda_{\max }=285 \mathrm{~nm}\right)$ at the highest absorption intensity, as shown in Figure 5 . The percentage of sulfur removed was calculated through the following relationship:

$$
\text { S removal } \%=\frac{\text { Conc. } i-\text { Conc.t }}{\text { Conc. } i} \times 100
$$

Where Conc. $\mathrm{i}=$ initial concentration of sulfur $(1000$ $\mathrm{ppm}$ ) represented by concentration of organic sulfur compound (DBT), Conc.t = sulfur concentration at certain time in a specific conditions (DBT) concentration.

\section{Characterization and analysis data}

Several physical and spectral methods were used; the ${ }^{1} \mathrm{H}-\mathrm{NMR}$ was investigated by Bruker Avance DPX $400 \mathrm{MHz}$ using DMSO- $\mathrm{d}_{6}$ as solvent. Trio-1000 equipment was used for mass spectroscopy; the elemental analysis was investigated by Flash EA 1112 Series Thermo Electron Corporation. The FT $\backslash$ IR measured by JASCO Canvas 4200, Avanta 2.02 software for atomic absorption by SensAA GCB scientific equipment system. METTLER Toledo TGAI DSC used for thermal analysis at $30-950{ }^{\circ} \mathrm{C}$ with a ramping heat rate of $10^{\circ} \mathrm{C} / \mathrm{min}$ under air, STARe evaluation software. The sulfur content was measured by Shimadzu UV-Vis 1800 spectrometer at $\left(\lambda_{\max }=285 \mathrm{~nm}\right)$. Table (1) shows some physical properties of prepared compounds.

Table 1: Some physical properties of prepared compounds.

\begin{tabular}{ccccc}
\hline No. & Compound & Conductivity* & m.p. ${ }^{\circ} \mathbf{C}$ & Color \\
\hline 1 & {$[\mathrm{MMPip}] \mathrm{I}$} & 100 & 85 & Off white \\
2 & {$[\mathrm{MMPip}] \mathrm{I} / \mathrm{FeCl}_{3}$} & 90 & 70 & Brown \\
3 & {$[\mathrm{MMPip}] \mathrm{I} / 2 \mathrm{FeCl}_{3}$} & 90 & 68 & Dark brown \\
4 & {$[\mathrm{MMPip}] \mathrm{I} / 3 \mathrm{FeCl}_{3}$} & 90 & 68 & Dark brown \\
\hline$*$ Conductivity $\left(\mathrm{ohm}^{-1} \cdot \mathrm{mol}^{-1} \cdot \mathrm{cm}^{2}\right)$ at $\left(25^{\circ} \mathrm{C}\right)$ and $\left(10^{-3} \mathrm{M}\right)$ by using water as solvent
\end{tabular}

\section{RESULTS AND DISCUSSION}

\section{Characterization data}

The characterization of the cation in the ionic liquids [MMPip] ${ }^{+}$by ${ }^{1} \mathrm{H}-\mathrm{NMR}$ (DMSO-d $6,400 \mathrm{MHz}$ ): $\delta 0.9409$ $\left(3 \mathrm{H}-\mathrm{CH}_{3}, \mathrm{~d}, J=11.52 \mathrm{~Hz}\right), \delta 1.6512\left(5 \mathrm{H}-\mathrm{CH}, 2 \mathrm{CH}_{2}\right.$, $\mathrm{m}), \delta 2.7547\left(3 \mathrm{H}-\mathrm{CH}_{3}, \mathrm{~s}\right), \delta 3.0718\left(4 \mathrm{H}-2 \mathrm{CH}_{2}, \mathrm{~m}\right)$, $\delta 8.2942(1 \mathrm{H}-\mathrm{NH}, \mathrm{br})$.

[MMPip]I (1) Anal. Calcd. for $\mathrm{C}_{7} \mathrm{H}_{16} \mathrm{IN}: \mathrm{C}, 34.87 ; \mathrm{H}$, $6.69 ; \mathrm{N}, 5.81$. Found: C, 35.89; $\mathrm{H}, 6.84 ; \mathrm{N}, 5.61$.

[MMPip]I/FeCl $\mathrm{FeC}_{3}$ (2) Anal. Calcd. for $\mathrm{C}_{7} \mathrm{H}_{16} \mathrm{Cl}_{3} \mathrm{FeIN}$ : C, 20.85; H, 4.00; Cl, 26.37; Fe, 13.85; N, 3.47 .
Found: $\mathrm{C}, 19.25 ; \mathrm{H}, 3.76 ; \mathrm{Cl}, 27.66 ; \mathrm{Fe}, 14.65 ; \mathrm{N}$, 3.22.

[MMPip]I/2 $\mathrm{FeCl}_{3}$ (3) Anal. Calcd. for $\mathrm{C}_{7} \mathrm{H}_{16} \mathrm{Cl}_{6} \mathrm{Fe}_{2} \mathrm{IN}$ : $\mathrm{C}, 14.87 ; \mathrm{H}, 2.85 ; \mathrm{Cl}, 37.61 ; \mathrm{Fe}, 19.75 ; \mathrm{N}, 2.48$. Found: $\mathrm{C}, 13.05 ; \mathrm{H}, 2.66 ; \mathrm{Cl}, 39.05 ; \mathrm{Fe}, 21.55 ; \mathrm{N}$, 2.22.

[MMPip]I/3FeCl 3 (4) Anal. Calcd. for $\mathrm{C}_{7} \mathrm{H}_{16} \mathrm{C}_{19} \mathrm{Fe}_{3} \mathrm{IN}$ : $\mathrm{C}, 11.55 ; \mathrm{H}, 2.22 ; \mathrm{Cl}, 43.84 ; \mathrm{Fe}, 23.02 ; \mathrm{N}, 1.92$. Found: $\mathrm{C}, 9.75 ; \mathrm{H}, 1.98 ; \mathrm{Cl}, 42.76 ; \mathrm{Fe}, 24.25 ; \mathrm{N}$, 1.75. Figure 1 shows the ${ }^{1} \mathrm{H}-\mathrm{NMR}$ of [MMPip]I (1). 


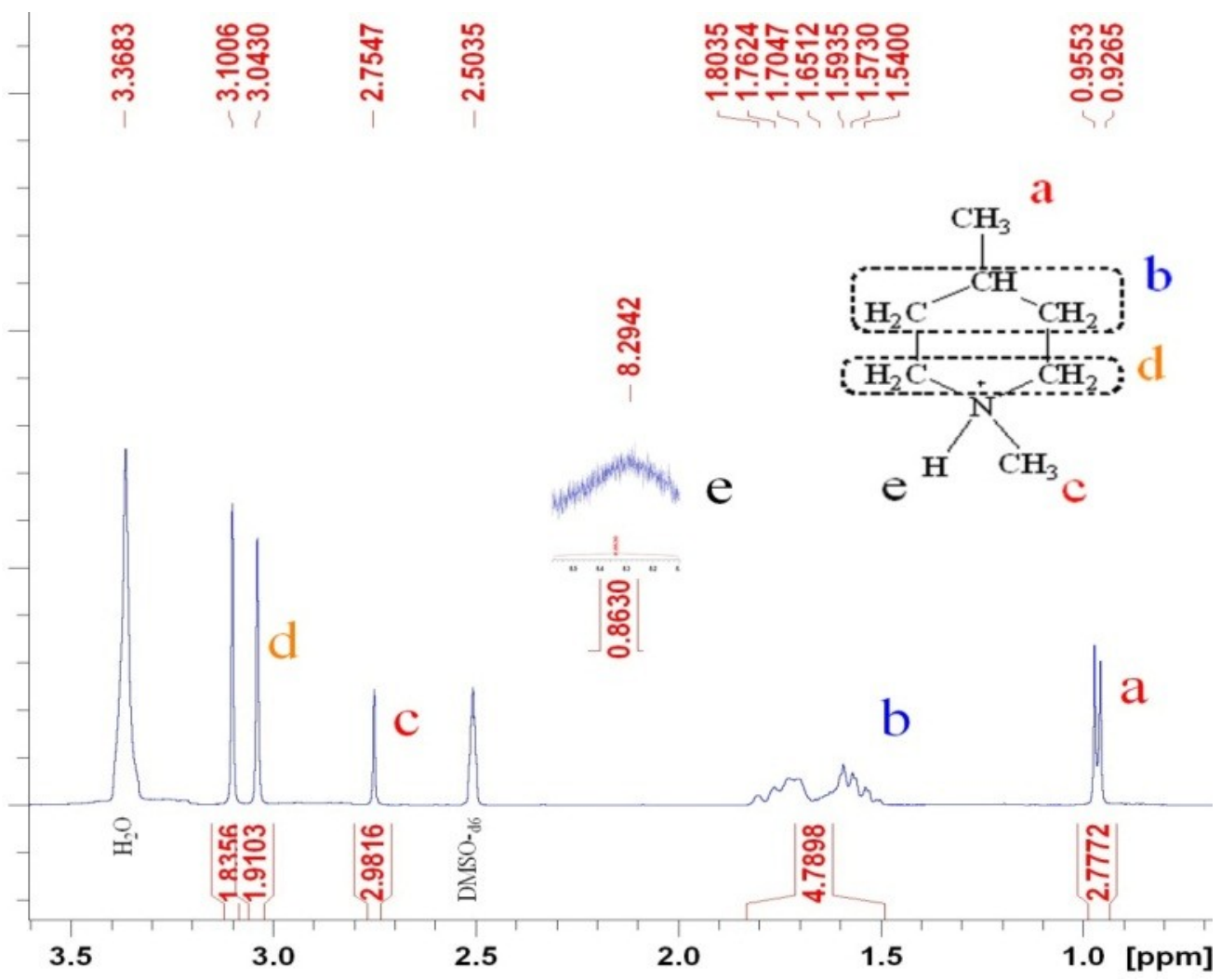

Figure 1: The ${ }^{1} \mathrm{H}-\mathrm{NMR}$ of [MMPip]I (1) (400 MHz, DMSO- $\mathrm{d}_{6}$ ).

The infrared spectrum measured the ionic liquid (organic salt) and the ionic liquid mixture with $\mathrm{FeCl}_{3}$. The results showed that the presence of Lewis acid makes slight displacements of some bands, and it may change the band's intensity (26-28). For example, a band appeared at $975 \mathrm{~cm}^{-1}$ due to the in-plane bending frequency of the $(\mathrm{C}-\mathrm{H})$ group and is shifted to a lower position when ferric chloride is present $(20,29)$. The bands observed at $1072 \mathrm{~cm}^{-1}$, $1454 \mathrm{~cm}^{-1}$ belong to (C-N str. or C-C str.) and (C$\mathrm{H}$, scissoring bending) respectively $(20,30)$. The other bands investigated are $2472 \mathrm{~cm}^{-1}\left(\mathrm{~N}^{+}-\mathrm{CH}_{3}\right.$ str.), $2734 \mathrm{~cm}^{-1}\left(\mathrm{~N}^{+}-\mathrm{H}\right.$ str. $), 2954 \mathrm{~cm}^{-1}$ (C-H symmetric str.). Figure 2 shows the IR spectra of ILs systems (20).

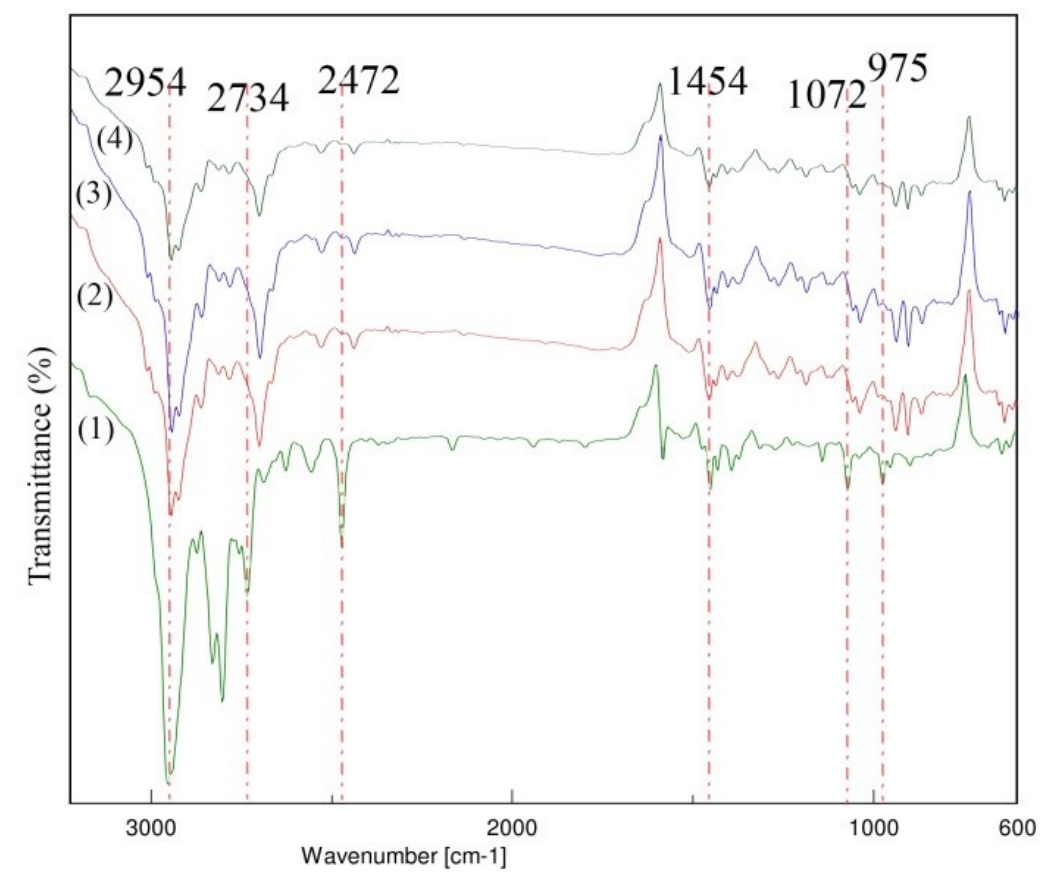

Figure 2: IR spectra of the IL systems: (1) [MMPip]I; (2) [MMPip]I/FeCl $3 ;$ (3) [MMPip]I/2FeCl $\mathrm{F}_{3}$ (4) $[\mathrm{MMPip}] \mathrm{I} / 3 \mathrm{FeCl}_{3}$ 


\section{Thermal study data}

The thermal stability of [MMPip]I and its mixtures with ferric chloride was studied. A noticeable decrease in the melting point of compounds containing ferric chloride was revealed. The study was under thermal conditions $\left(30-950{ }^{\circ} \mathrm{C}\right.$ ) and a temperature rampage rate $\left(15^{\circ} \mathrm{C} / \mathrm{min}\right)$. The results showed that the ionic liquid [MMPip]I is stable at temperatures up to $250^{\circ} \mathrm{C}$; as shown in Figure 3, the thermal degradation process occurs in one main stage $(21,31,32)$. Although the presence of ferric chloride increases the presence of moisture water in the compound, as the results showed, the moisture water loses by cycling to $110{ }^{\circ} \mathrm{C}$. Thus, the [MMPip]I/ $\mathrm{nFeCl}_{3}$ compounds have two main stages of thermal degradation. However, all mixes are relatively stable at the temperature of experimental conditions of the process (EDS). Figure 4 shows the thermal gravimetric analysis of the compounds.

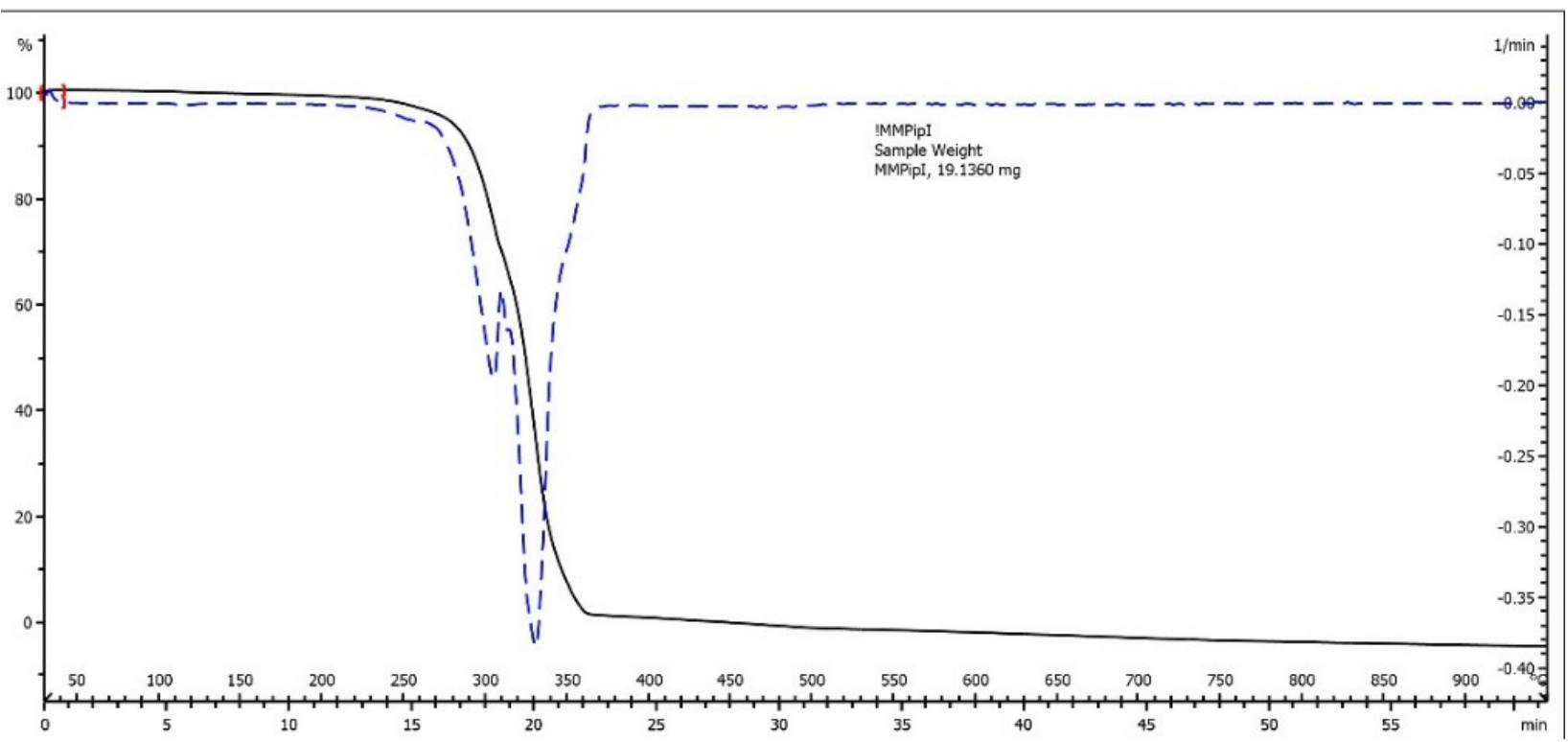

Figure 3: TGA and DTA of [MMPip]I.

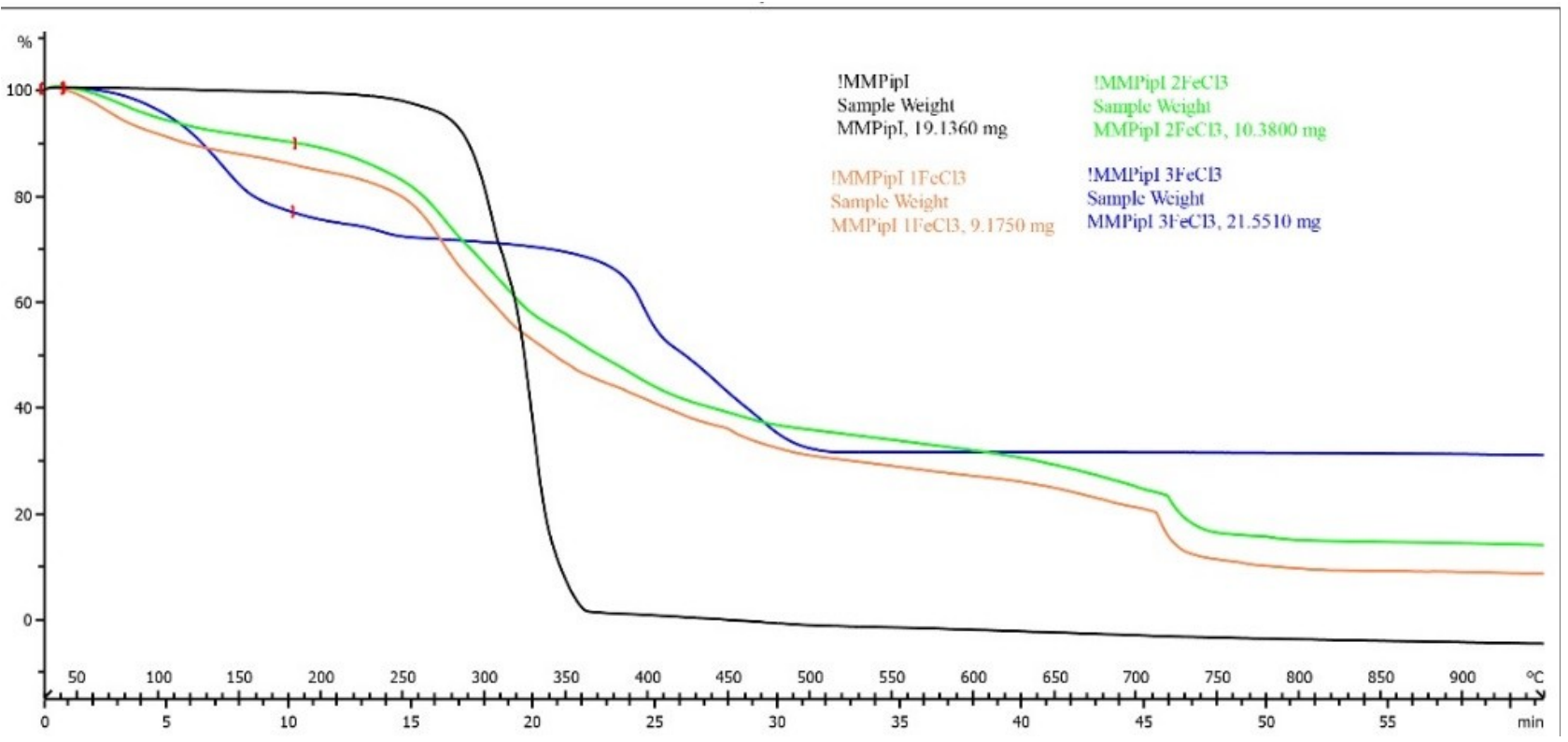

Figure 4: TGA analysis of [MMPip]I and its $\mathrm{FeCl}_{3}$ mixtures.

Data for desulfurization analysis

Completing the standard curve by measuring the compound (DBT) absorbance for several standard concentrations (250,500, 750, and $1000 \mathrm{ppm})$, as shown in Figure 5. 


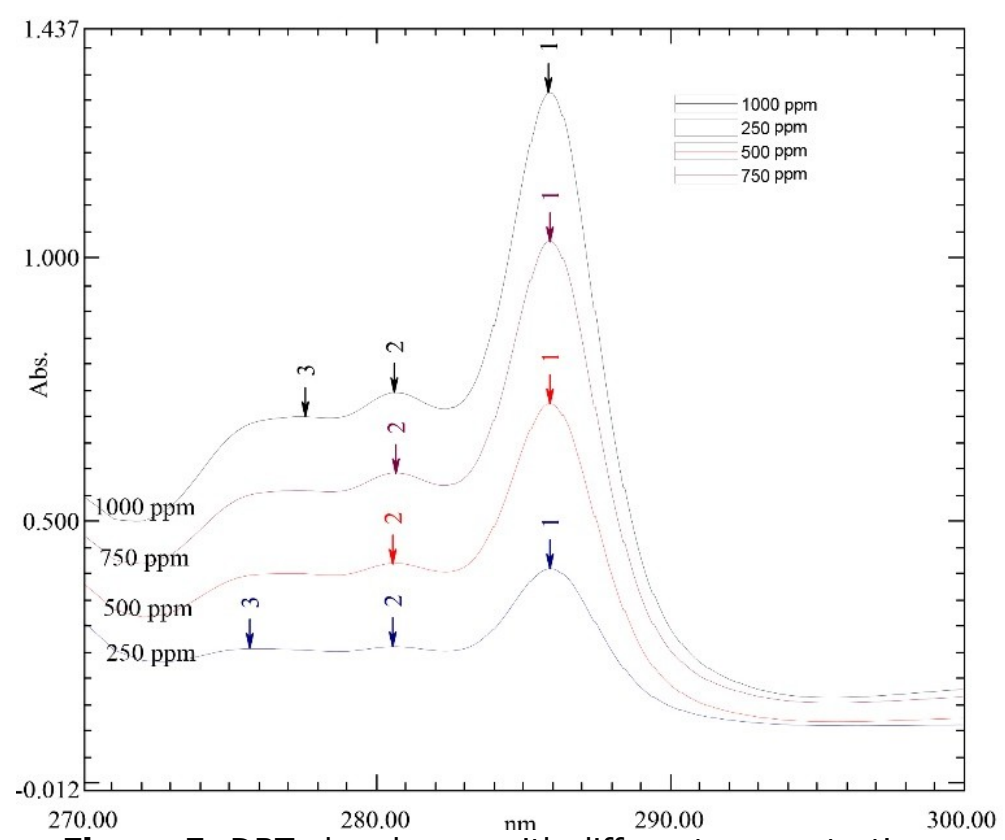

Figure 5: DBT absorbance with different concentrations.

The optimum conditions for the (EDS) process were determined by treating the model oil with prepared compounds for extraction at multiple temperatures $\left(15,30,45^{\circ} \mathrm{C}\right)$ using a fixed weight of the extracted materials $(0.05 \mathrm{~g})$ and 30 minutes. The results showed an increase in the removal efficiency with an increase in temperature. These results have good similarities to the literature $(18,20,33)$, noting that there was no significant increase in efficiency when the temperature was increased from $30^{\circ} \mathrm{C}$ to $45^{\circ} \mathrm{C}$, and it is preferable to use the laboratory temperature because it is more controllable, as shown in Figure 6. After stabilizing the temperature, the optimum time was verified under $30{ }^{\circ} \mathrm{C}$ and using the weight of the extracted substance $(0.05$ g). The results showed that the removal process increases with the increase of time, which have slightly different from the literature (20), and there is no significant difference between 60 minutes and 90 minutes, as the equilibrium is almost stable after 60 minutes and as illustrated in Figure 7. Finally, the efficiency was tested using many different weights, as the results showed that with the increase in the amount of extracted material, the extraction efficiency increases Figure 8.

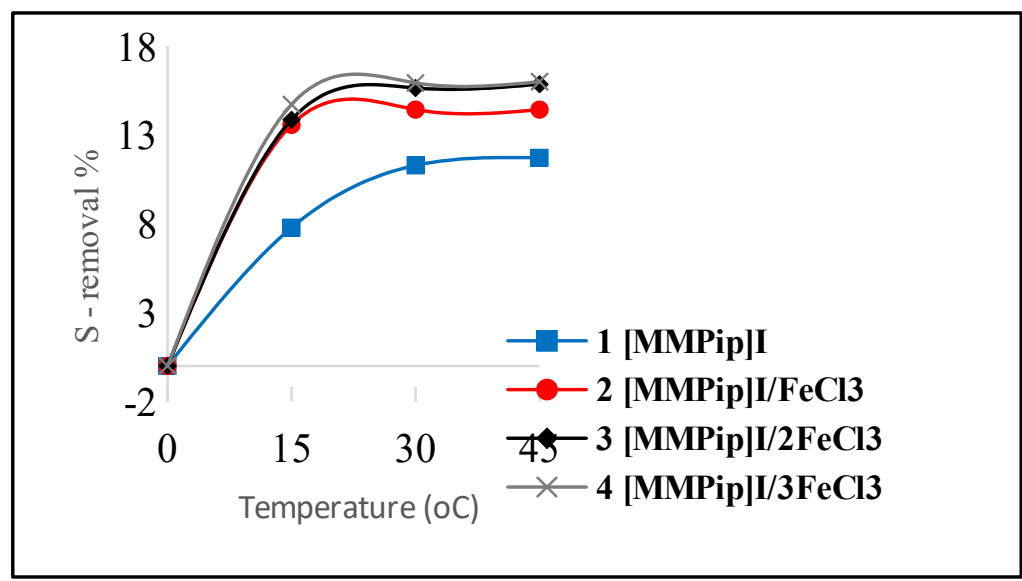

Figure 6: Effect of temperature: extractant used $0.05 \mathrm{~g}, 30 \mathrm{~min}$. 


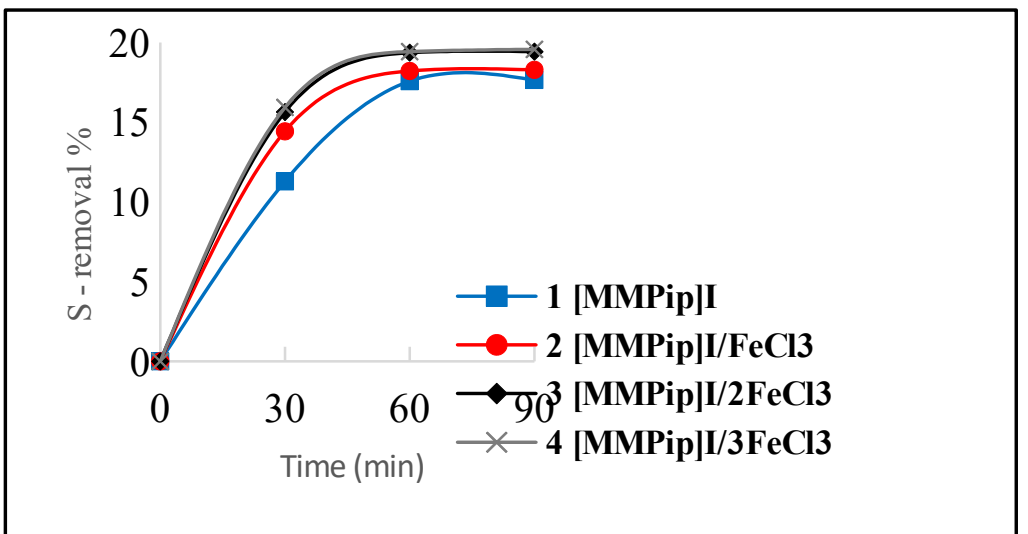

Figure 7: Effect of time: extractant used $0.05 \mathrm{~g}, 30^{\circ} \mathrm{C}$.

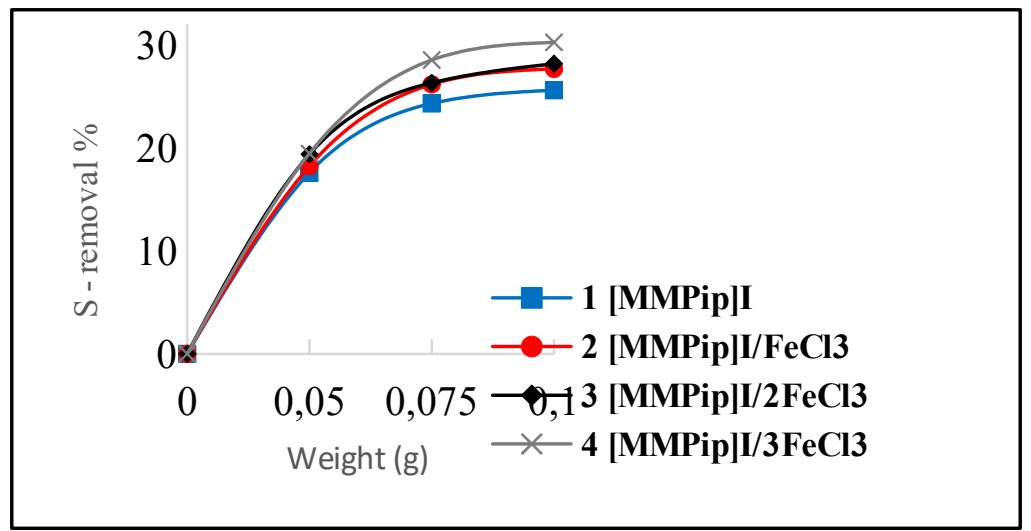

Figure 8: Effect of extractant weight: $60 \mathrm{~min}, 30^{\circ} \mathrm{C}$.

Through these results, it is noted that the increase in temperature from $30^{\circ} \mathrm{C}$ to $45^{\circ} \mathrm{C}$ and the increase in the time for the extraction process after 60 minutes does not significantly affect the efficiency of the extraction process, while the increase in the weight of the extracted material (ionic liquid or ionic liquid containing Lewis acid) is more considerable and more clearly. By comparing the results, we find that the highest percentage of sulfur removal is when using $0.1 \mathrm{~g}$ of compound (I), which is rather good when compared to efficiency results of up to $100 \%$, but by using high amounts of the extracted substance to the oil model $(18,20)$. It also noted that the efficiency of the removal ratio increases with the increase in the ratio of ferric chloride to the ionic liquid, which is consistent with the published research $(19,34,35)$.

The proposed mechanism for the extraction of organic sulfur compounds is through the interactions between the $\Pi$ electrons of organic sulfur compounds (DBT) with $n$ electrons of the ionic liquid and their interaction with the metallic element in Lewis acid $(36,37)$. The results showed that ionic liquid mixed with Lewis acid has a higher extraction efficiency than the ionic liquid alone and higher than the use of Lewis acid alone, and the extraction process is more selective for aromatic sulfur compounds $(17,20,21)$.

\section{CONCLUSION}

The pyridinium base's ionic liquid and salt were prepared with ferric chloride as Lewis acid, and their efficiency was tested in extracting the organic sulfur compounds from the petroleum model. It was found that the best extraction factor among the compounds used is [MMPip]I/3FeCl 3 , where the percentage of sulfur removal from the oil model was $(30 \%)$ under the optimal conditions $(10 \mathrm{~mL}$ of model oil of $1000 \mathrm{ppm}$ DBT, $0.1 \mathrm{~g}$ of extractant, 60 $\min$ at $30^{\circ} \mathrm{C}$ ). Compared with the previous work, these results are considered promising due to the use of acceptable quantities of the extracted agent relative to the quantity of the oil model used. It also noticed that the extraction efficiency increased with the increase in Lewis acid (ferric chloride) ratio to the ionic liquid under the same experimental conditions for the extraction process.

\section{ACKNOWLEDGEMENT}

The author is grateful to the University of Mosul for their support of scientific research and the Department of Chemistry at the University of Liverpool for helping to carry out some of the required research measurements. 


\section{REFERENCES}

1. Corma A, Martínez C, Ketley G, Blair G. On the mechanism of sulfur removal during catalytic cracking. Applied Catalysis A: General. 2001 Feb;208(1-2):135-52.

2. Ito $E$, van Veen JAR. On novel processes for removing sulphur from refinery streams. Catalysis Today. 2006 Sep;116(4):446-60.

3. Mei $H$, Mei BW, Yen TF. A new method for obtaining ultra-low sulfur diesel fuel via ultrasound assisted oxidative desulfurization is. Fuel. 2003 Mar;82(4):405-14.

4. Xie $Y$, Chowdhury $M$, Bhavsar $P$, Zhou $Y$. An integrated modeling approach for facilitating emission estimations of alternative fueled vehicles. Transportation Research Part D: Transport and Environment. 2012 Jan;17(1):15-20.

5. Armstrong JP, Hurst $C$, Jones RG, Licence $P$ Lovelock KRJ, Satterley $\mathrm{CJ}$, et al. Vapourisation of ionic liquids. Phys Chem Chem Phys. 2007;9(8):982.

6. Yang RT. Desulfurization of Transportation Fuels with Zeolites Under Ambient Conditions. Science. 2003 Jul 4;301(5629):79-81.

7. Babich I. Science and technology of nove processes for deep desulfurization of oil refinery streams: a review^. Fuel. 2003 Apr;82(6):607-31.

8. Agarwal P, Sharma DK. Comparative Studies on the Bio-desulfurization of Crude Oil with Other Desulfurization Techniques and Deep Desulfurization through Integrated Processes. Energy Fuels. 2010 Jan $21 ; 24(1): 518-24$.

9. Song Z, Zhou T, Qi Z, Sundmacher K. Systematic Method for Screening Ionic Liquids as Extraction Solvents Exemplified by an Extractive Desulfurization Process. ACS Sustainable Chem Eng. 2017 Apr 3;5(4):3382-9.

10. Domańska $U$, Wlazło M. Effect of the cation and anion of the ionic liquid on desulfurization of model fuels. Fuel. 2014 Oct; 134:114-25.

11. Lu X, Yue L, Hu M, Cao Q, Xu L, Guo Y, et al. Piperazinium-Based Ionic Liquids with Lactate Anion for Extractive Desulfurization of Fuels. Energy Fuels. 2014 Mar 20;28(3):1774-80.

12. Zhao H, Baker GA, Wagle DV, Ravula S, Zhang Q. Tuning Task-Specific Ionic Liquids for the Extractive Desulfurization of Liquid Fuel. ACS Sustainable Chem Eng. 2016 Sep 6;4(9):4771-80.
13. Flieger J, Flieger M. Ionic Liquids Toxicity Benefits and Threats. IJMS. 2020 Aug $29 ; 21(17): 6267$.

14. Zhao $Y$, Bostrom T. Application of ionic liquids in solar cells and batteries: a review. Current Organic Chemistry. 2015;19(6):556-66.

15. Kulkarni PS, Afonso CAM. Deep desulfurization of diesel fuel using ionic liquids: current status and future challenges. Green Chem. 2010;12(7):1139.

16. Holbrey JD, López-Martin I, Rothenberg G, Seddon KR, Silvero G, Zheng X. Desulfurisation of oils using ionic liquids: selection of cationic and anionic components to enhance extraction efficiency. Green Chem. 2008;10(1):87-92.

17. Dharaskar SA, Wasewar KL, Varma MN, Shende DZ. Extractive Deep Desulfurization of Liquid Fuels Using Lewis-Based Ionic Liquids. Journal of Energy. 2013;2013:1-4.

18. Ko NH, Lee JS, Huh ES, Lee $H$, Jung KD, Kim $\mathrm{HS}$, et al. Extractive Desulfurization Using FeContaining Ionic Liquids. Energy Fuels. 2008 May $1 ; 22(3): 1687-90$.

19. Bösmann $A$, Datsevich $L$, Jess $A$, Lauter $A$, Schmitz C, Wasserscheid P. Deep desulfurization of diesel fuel by extraction with ionic liquids. Chem Commun. 2001 Nov 22;(23):2494-5.

20. Zhang L, Wang J, Sun Y, Jiang B, Yang H. Deep oxidative desulfurization of fuels by superbasederived Lewis acidic ionic liquids. Chemical Engineering Journal. 2017 Nov;328:445-53.

21. Zhang M, Zhu W, Xun S, Li H, Gu Q, Zhao Z, et al. Deep oxidative desulfurization of dibenzothiophene with POM-based hybrid materials in ionic liquids. Chemical Engineering Journal. 2013 Mar;220:328-36

22. Buttrus NH, Sabah AA, Taqa AA, Englert U. 3Allyl-1-methyl-1 H -benzotriazol-3-ium iodide. Acta Crystallogr E Struct Rep Online. 2012 Sep $15 ; 68(9): 02735-02735$.

23. Singh SK, Savoy AW. Ionic liquids synthesis and applications: An overview. Journal of Molecular Liquids. 2020 Jan;297:112038.

24. Brown LC, Hogg JM, Swadźba-Kwaśny M. Lewis Acidic Ionic Liquids. In: Kirchner B, Perlt E, editors. Ionic Liquids II [Internet]. Cham: Springer International Publishing; 2017 [cited 2021 Sep 20]. p. 185-224. (Topics in Current Chemistry Collections). $\leq$ URL $>$

25. Zeng $S$, Liu L, Shang D, Feng J, Dong $H, X u Q$, et al. Efficient and reversible absorption of ammonia 
by cobalt ionic liquids through Lewis acid-base and cooperative hydrogen bond interactions. Green Chem. 2018;20(9):2075-83.

26. Mohammed EH, Ameen AM, Sabah AA, Mustafa TS, Sulyman SAA, Younus NG. Synthesis and Characterization of $\mathrm{Mn}$ (II), Fe (III), Co (II), Ni (II), and $\mathrm{Cu}$ (II) 1, 3-Dimethylbenzotrizolium Salt Complexes and Their Uses for Decreasing of Sulfur in Diesel Oil. Indian Journal of Heterocyclic Chemistry. 2020;30(04):565-70.

27. Kore $R$, Kelley Steven $P$, Aduri $P$, Rogers RD. Mixed metal double salt ionic liquids comprised of $\left[\mathrm{HN}_{222}\right]_{2}[\mathrm{ZnCl}]_{4}$ and $\mathrm{AlCl}_{3}$ provide tunable Lewis acid catalysts related to the ionic environment. Dalton Trans. 2018;47(23):7795-803.

28. Fainleib A, Grigoryeva O, Starostenko O, Vashchuk A, Rogalsky S, Grande D. Acceleration effect of ionic liquids on polycyclotrimerization of dicyanate esters. Express Polymer Letters. 2016;10(9): 722 .

29. Chen X, Guo H, Abdeltawab AA, Guan Y, AlDeyab SS, Yu G, et al. Brønsted-Lewis Acidic Ionic Liquids and Application in Oxidative Desulfurization of Diesel Fuel. Energy Fuels. 2015 May $21 ; 29(5): 2998-3003$.

30. Chan JW, Taylor DS, Zwerdling T, Lane SM, Ihara K, Huser T. Micro-Raman Spectroscopy Detects Individual Neoplastic and Normal Hematopoietic Cells. Biophysical Journal. 2006 Jan;90(2):648-56.

31. Montanino $M$, Carewska $M$, Alessandrini $F$, Passerini S, Appetecchi GB. The role of the cation aliphatic side chain length in piperidinium bis(trifluoromethansulfonyl)imide ionic liquids. Electrochimica Acta. 2011 Dec;57:153-9.

32. Salminen J, Papaiconomou N, Kumar RA, Lee JM, Kerr J, Newman J, et al. Physicochemical properties and toxicities of hydrophobic piperidinium and pyrrolidinium ionic liquids. Fluid Phase Equilibria. 2007 Dec;261(1-2):421-6.

33. Sabah AA. Synthesis and Characterization of Some Transition Metals Complex Salts of Pyridinium Iodide Ionic Liquids: Application on Extractive Desulfurization. Journal of the Turkish Chemical Society Section A: Chemistry. 2021 Jul $23 ; 8(3): 763-74$.

34. Song Z, Zhou T, Zhang J, Cheng H, Chen L, Qi $Z$. Screening of ionic liquids for solvent-sensitive extraction-with deep desulfurization as an example. Chemical Engineering Science. 2015 Jun;129:6977.

35. Wang S, Li P, Hao L, Deng C, Ren W, Lü $H$. Oxidative Desulfurization of Model Diesel Using a Fenton-Like Catalyst in the Ionic Liquid [Dmim]BF 4. Chem Eng Technol. 2017 Mar;40(3):555-60.

36. Wang Q, Lei L, Zhu J, Yang B, Li Z. Deep Desulfurization of Fuels by Extraction with 4Dimethylaminopyridinium-Based Ionic Liquids. Energy Fuels. 2013 Aug 15;27(8):4617-23.

37. Ren Z, Zhou Z, Li M, Zhang F, Wei L, Liu W. Deep Desulfurization of Fuels Using Imidazole Anion-Based Ionic Liquids. ACS Sustainable Chem Eng. 2019 Jan 22;7(2):1890-900. 


\section{Extractive Desulfurization Using Piperidinium Based Ionic Liquids with Lewis Acids}

Assim A. Sabah" ${ }^{*}$

Supporting Information

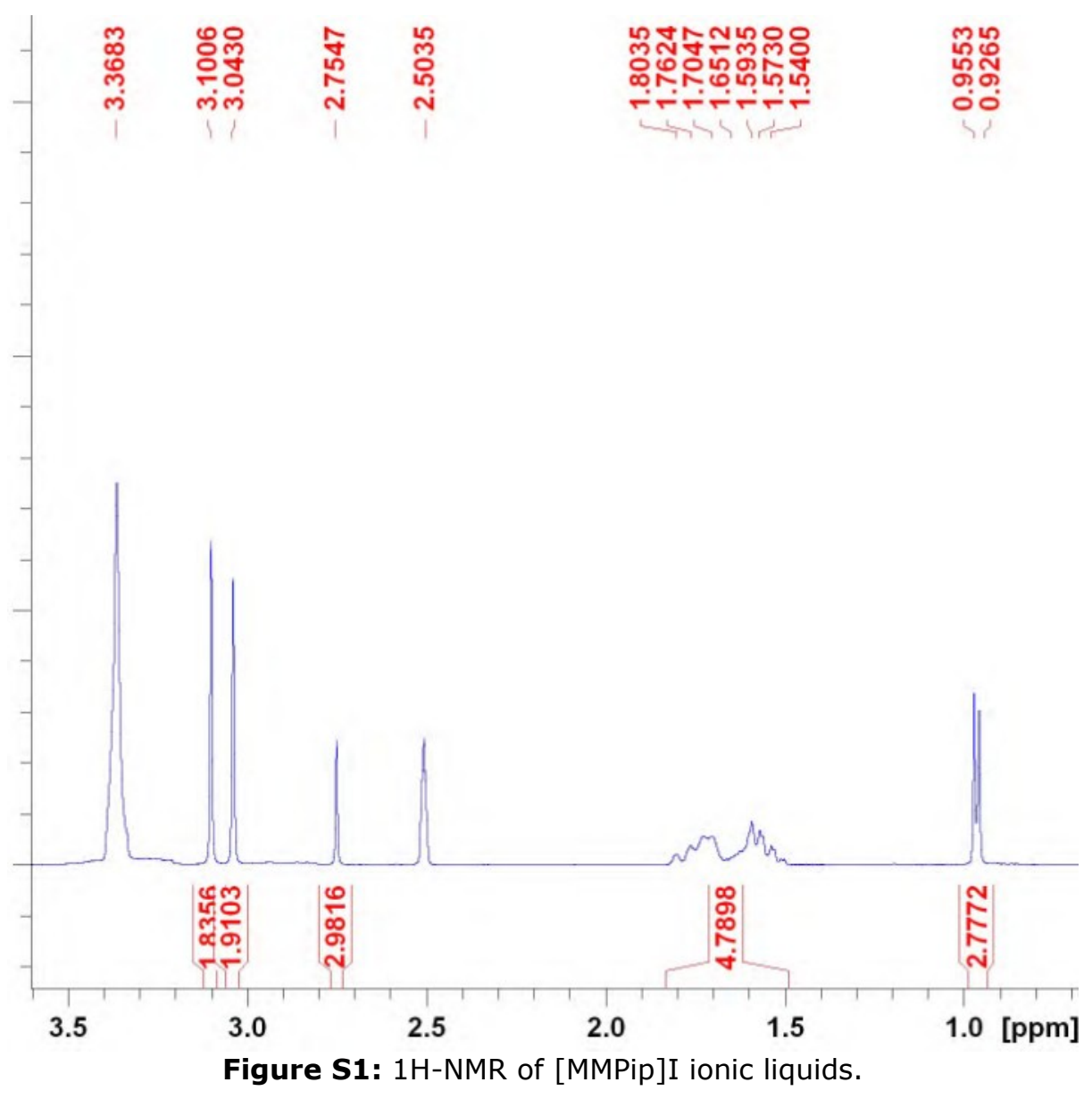



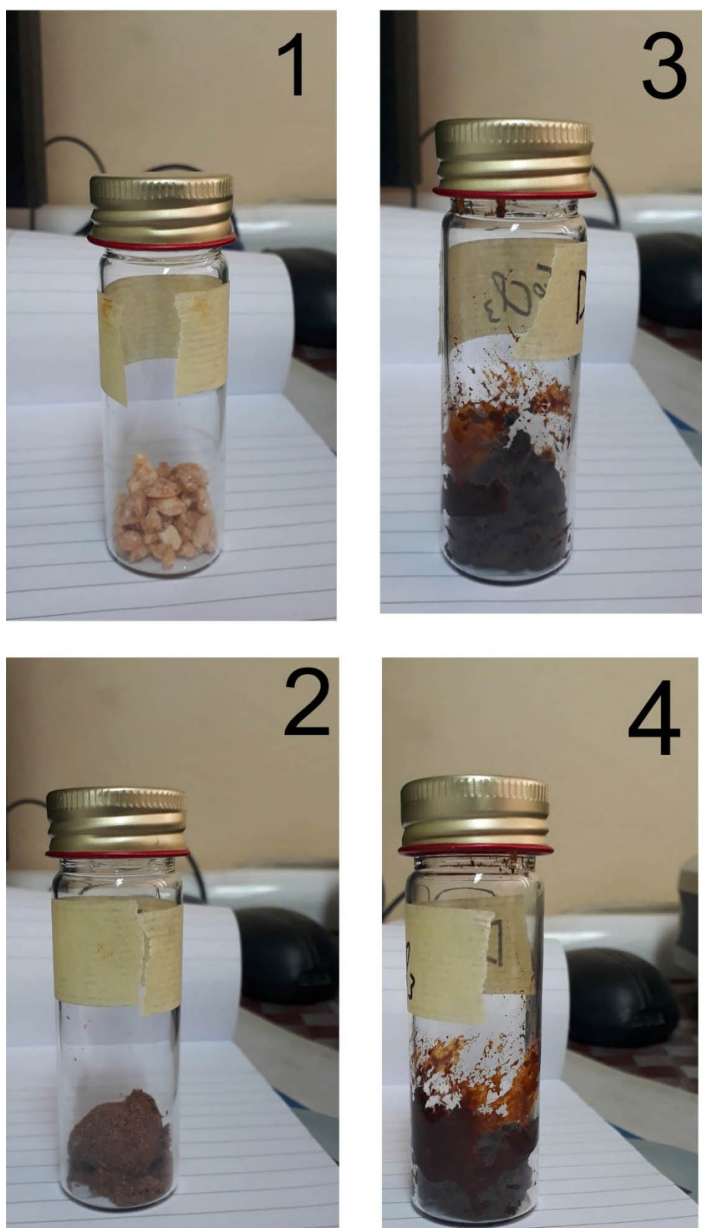

Figure S2: Pictures of the prepared compounds.

^exo

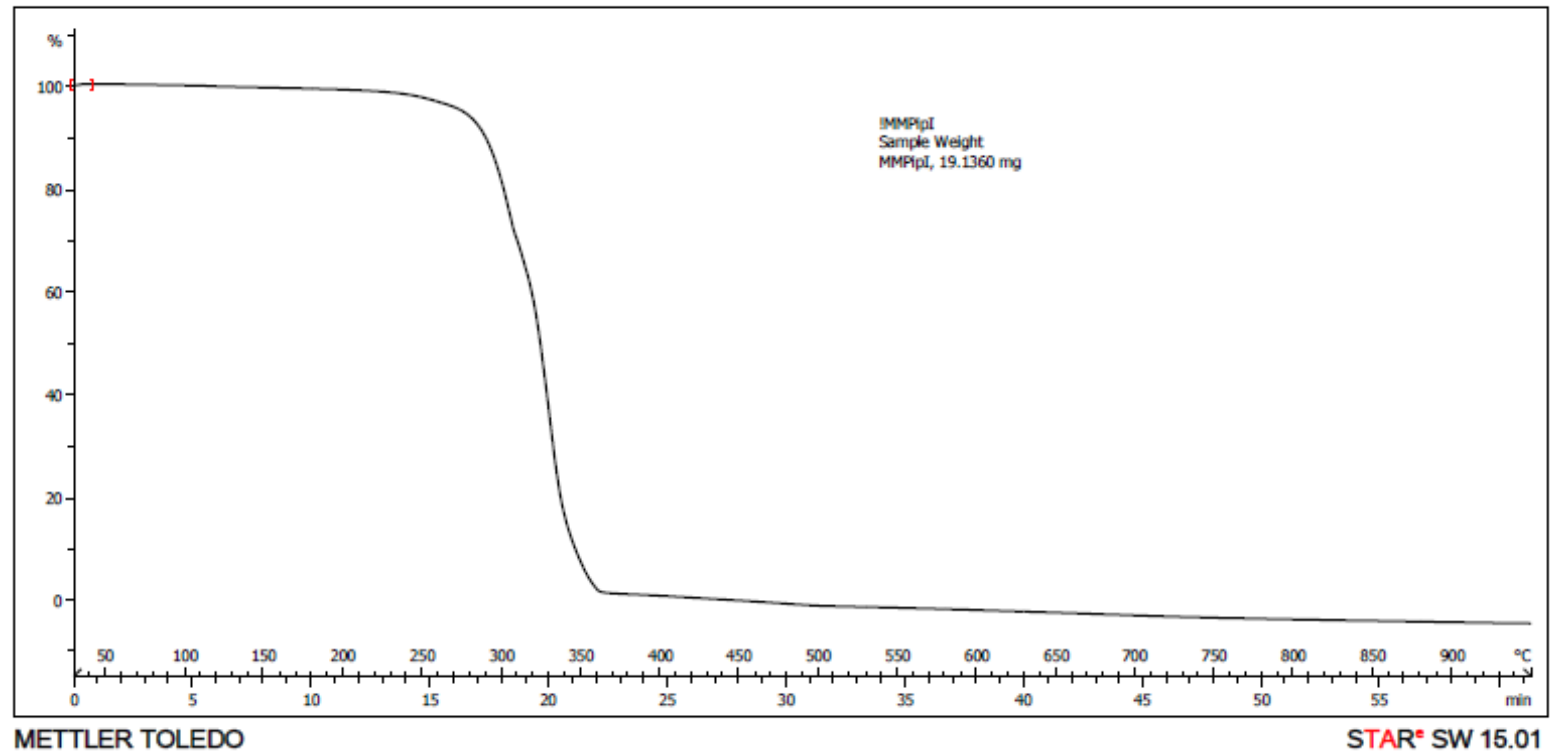

Figure S3: TGA analyses of [MMPip]I ionic liquids. 


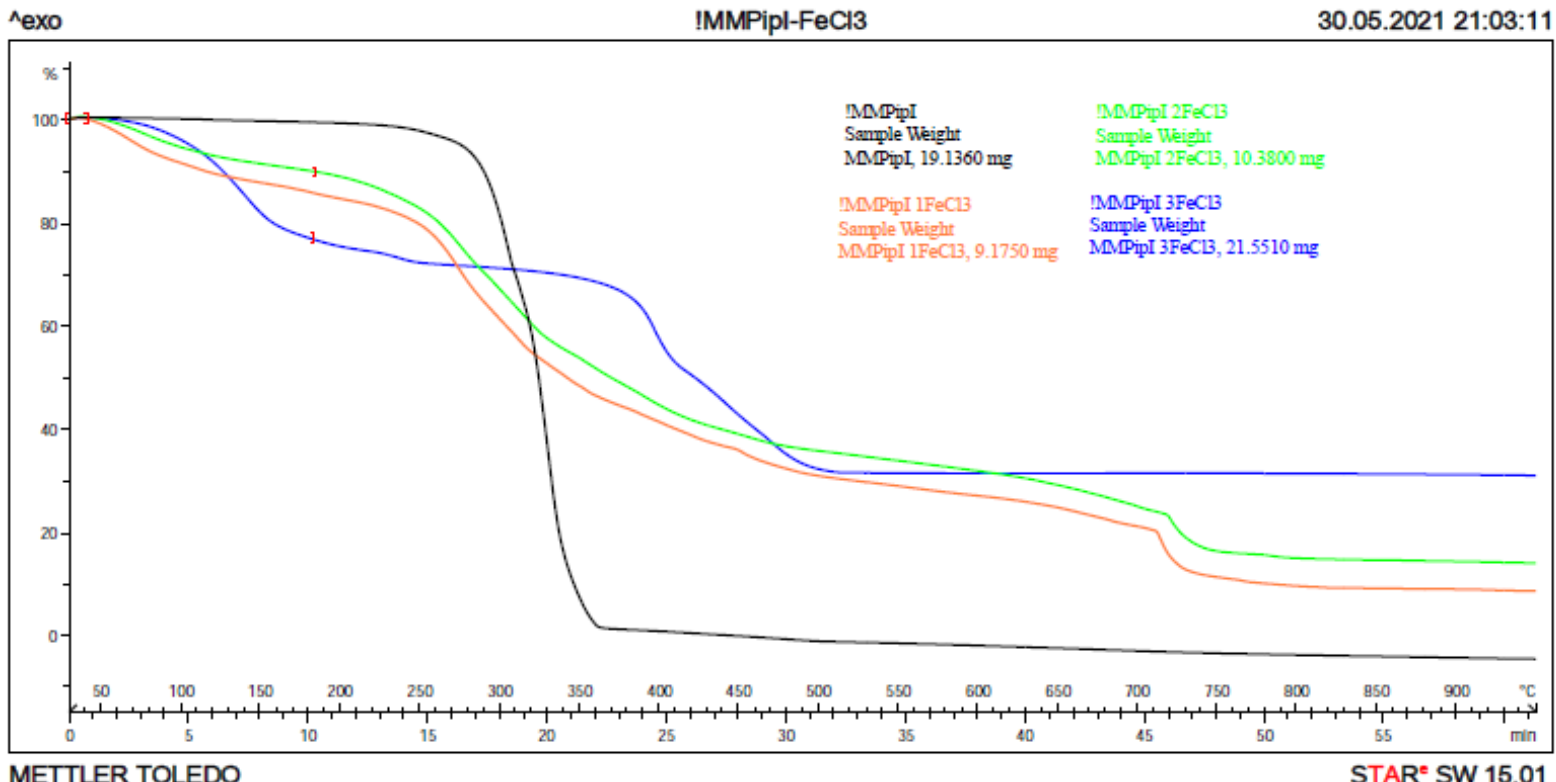

Figure S4: TGA analysis of prepared compounds.

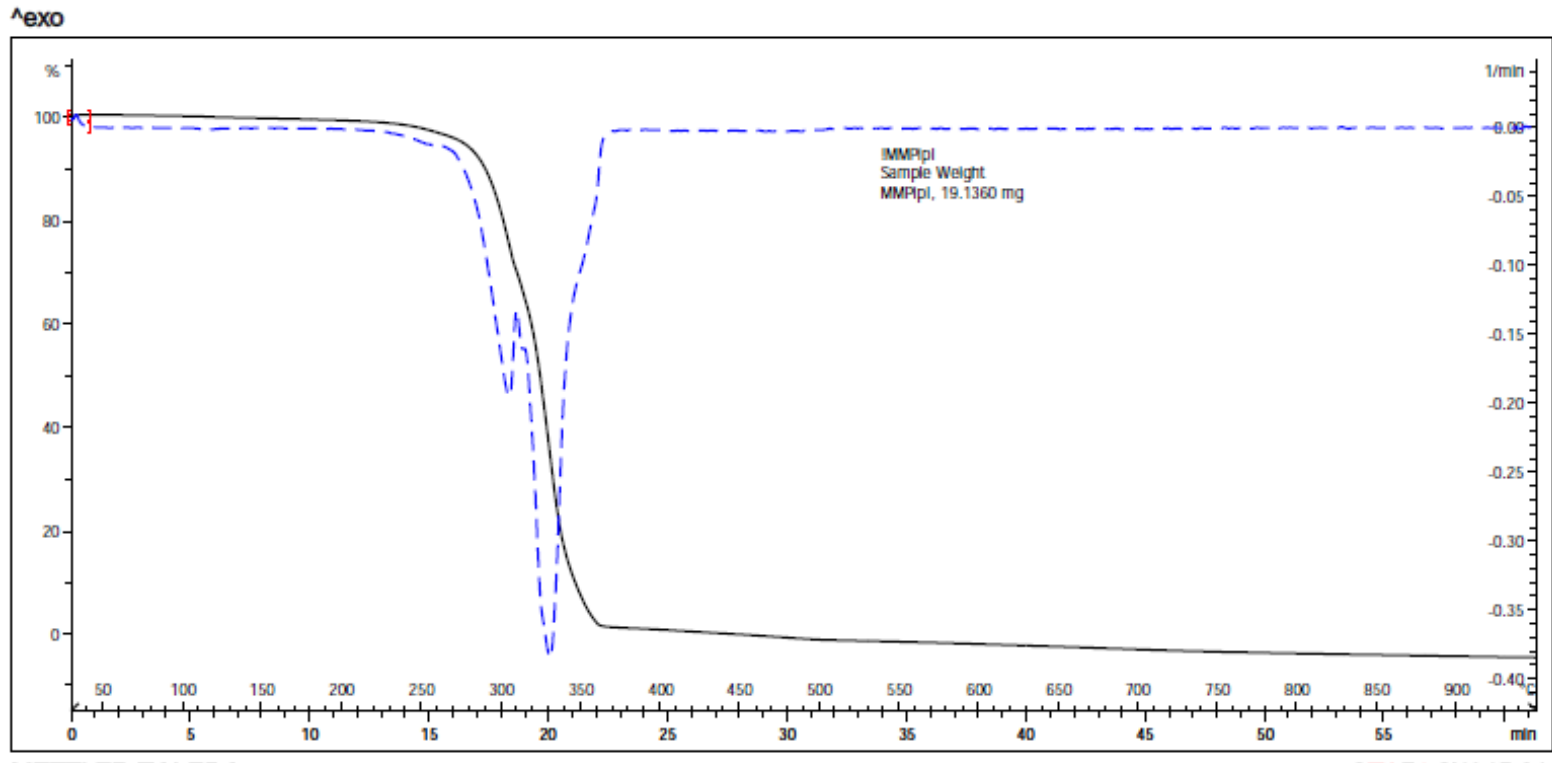

METTLER TOLEDO

Figure S5: TGA and DTA analyses of [MMPip]I ionic liquids. 


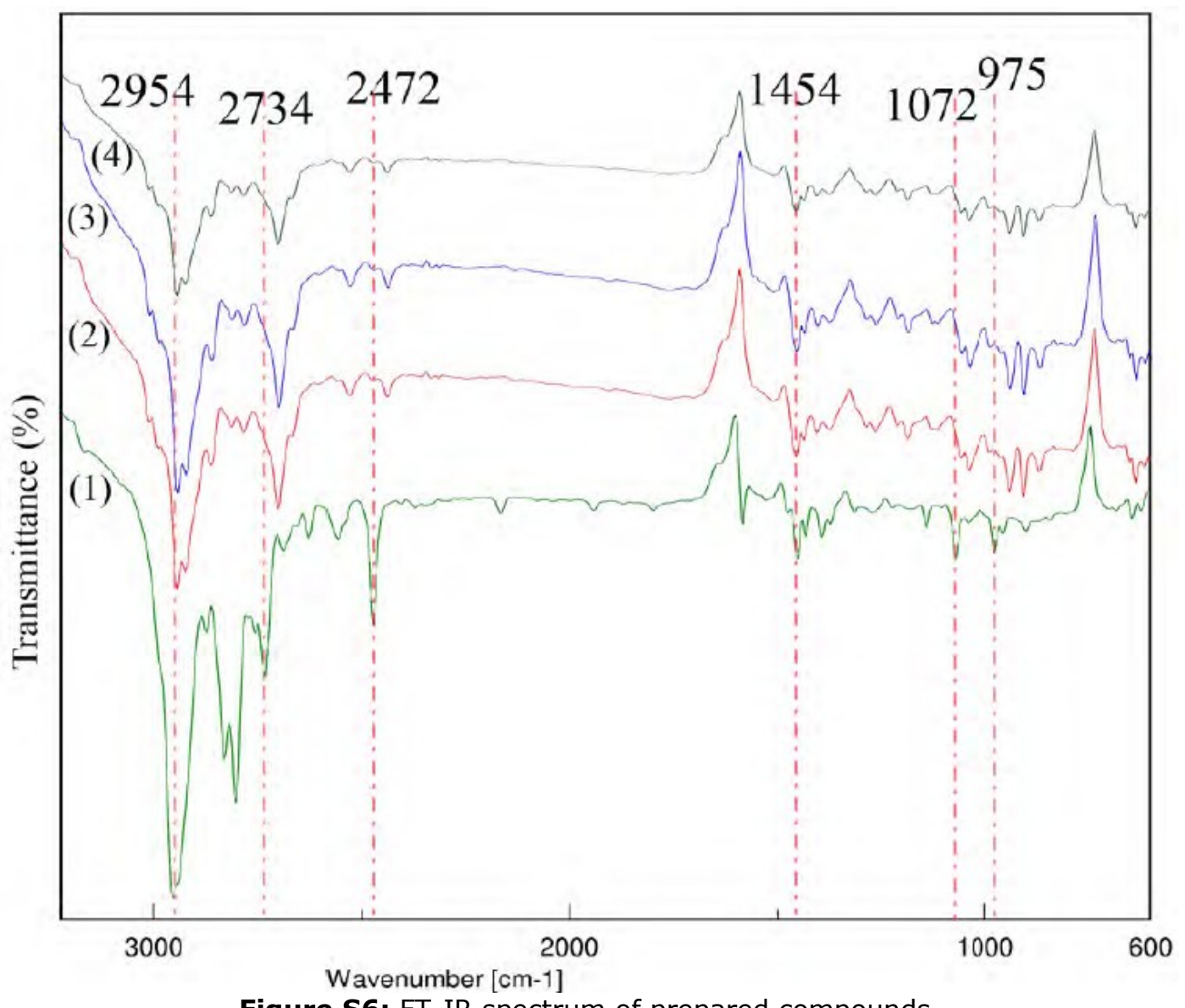

Figure S6: FT-IR spectrum of prepared compounds.

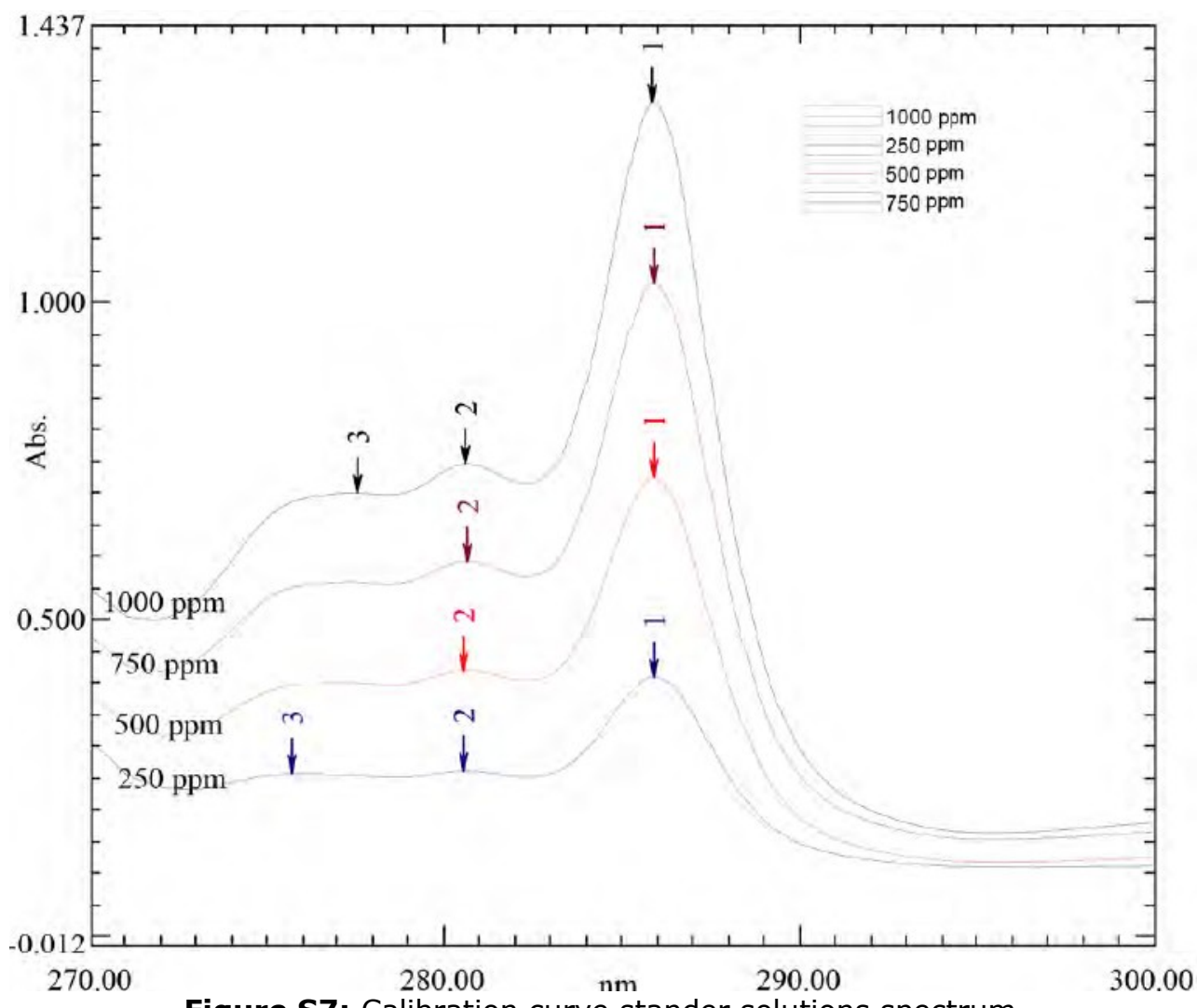

Figure S7: Calibration curve stander solutions spectrum. 


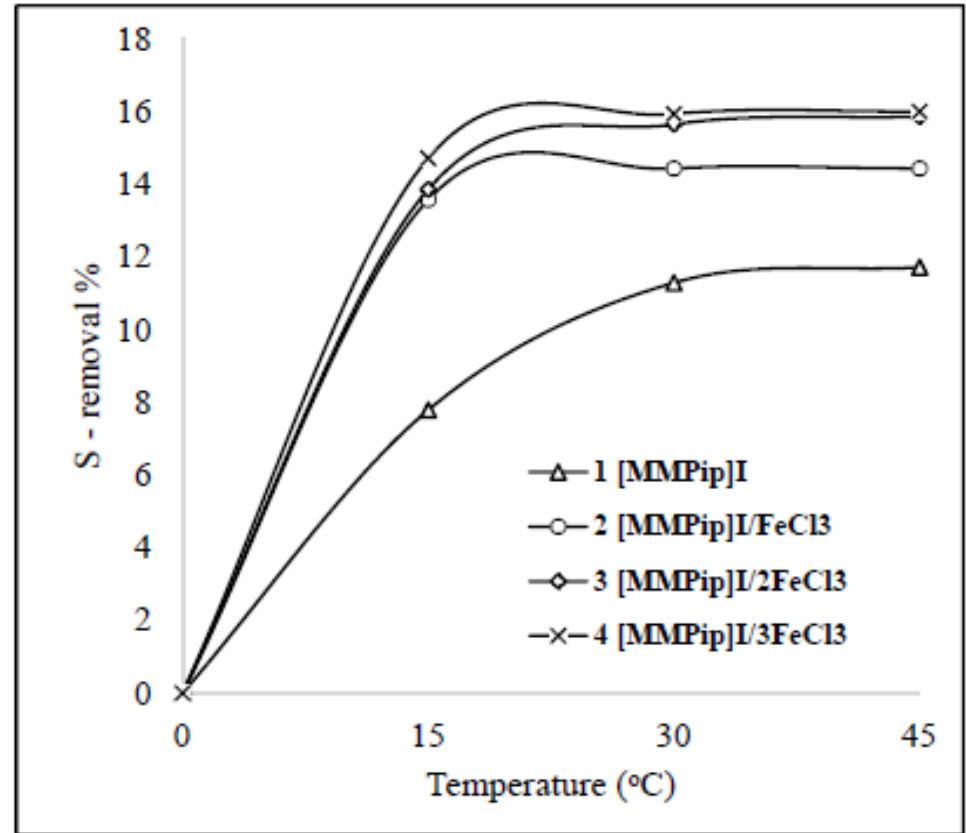

Figure S8: Effect of temperature: extractant used $0.05 \mathrm{~g}, 30 \mathrm{~min}$.

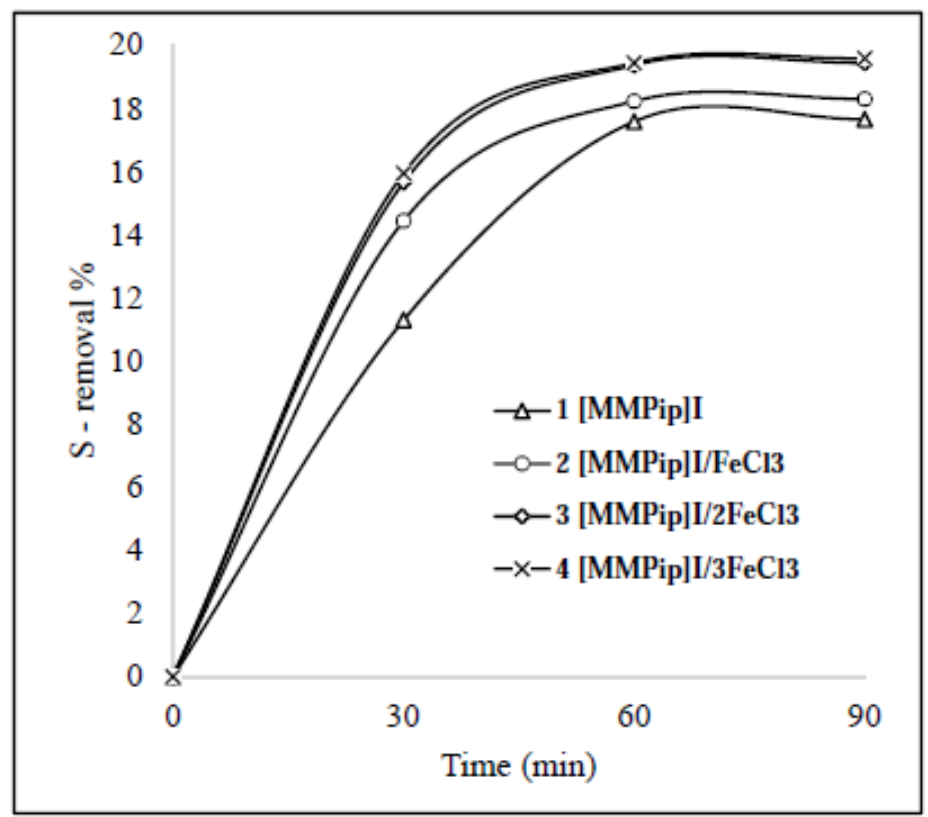

Figure 59: Effect of time: extractant used $0.05 \mathrm{~g}, 30^{\circ} \mathrm{C}$. 


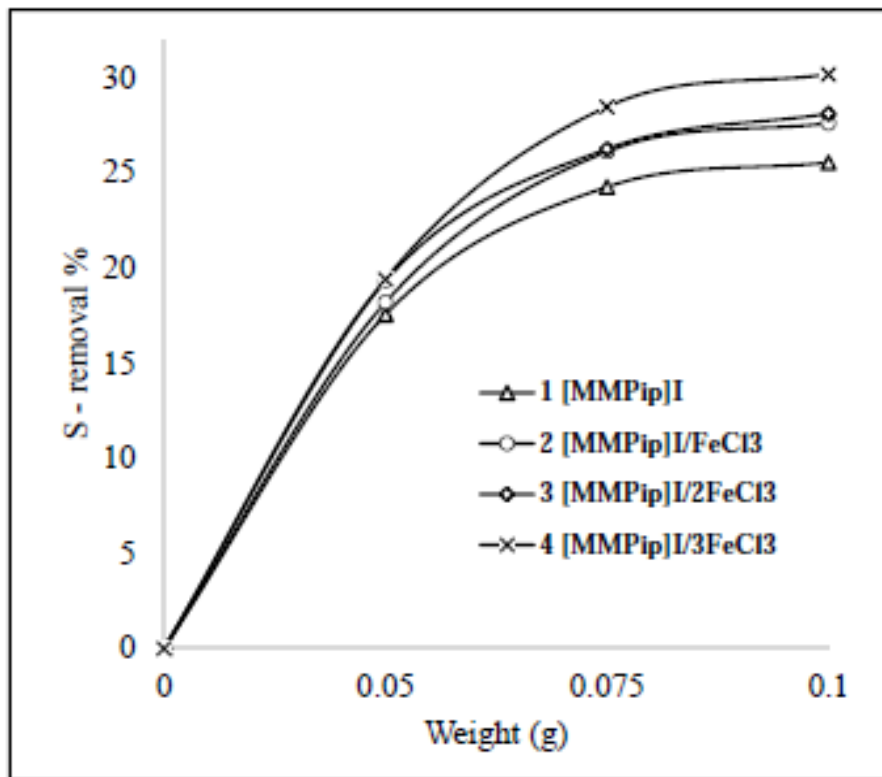

Figure S10: Effect of extractant weight: $60 \mathrm{~min}, 30^{\circ} \mathrm{C}$.

Data Set 250 - RawData

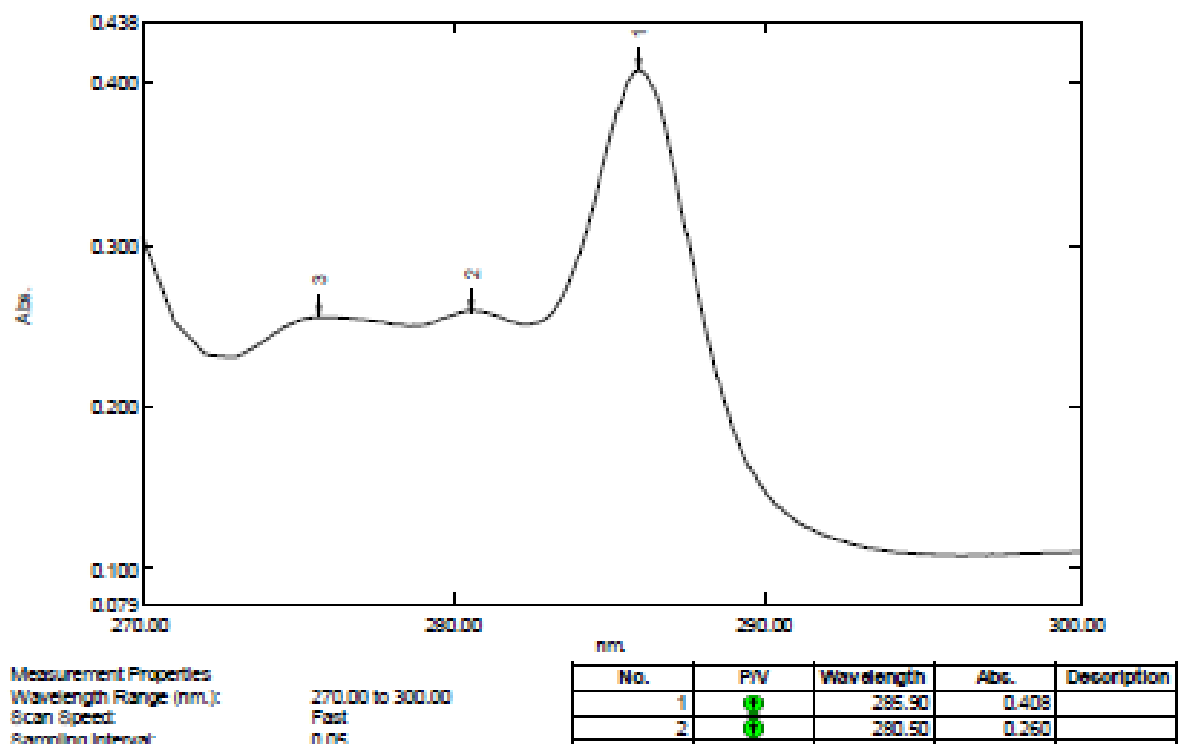

Figure S11: UV- Spectrum peak pick report of $250 \mathrm{ppm}$ of DBT stranded solution. 
Data Set 500 - RawData

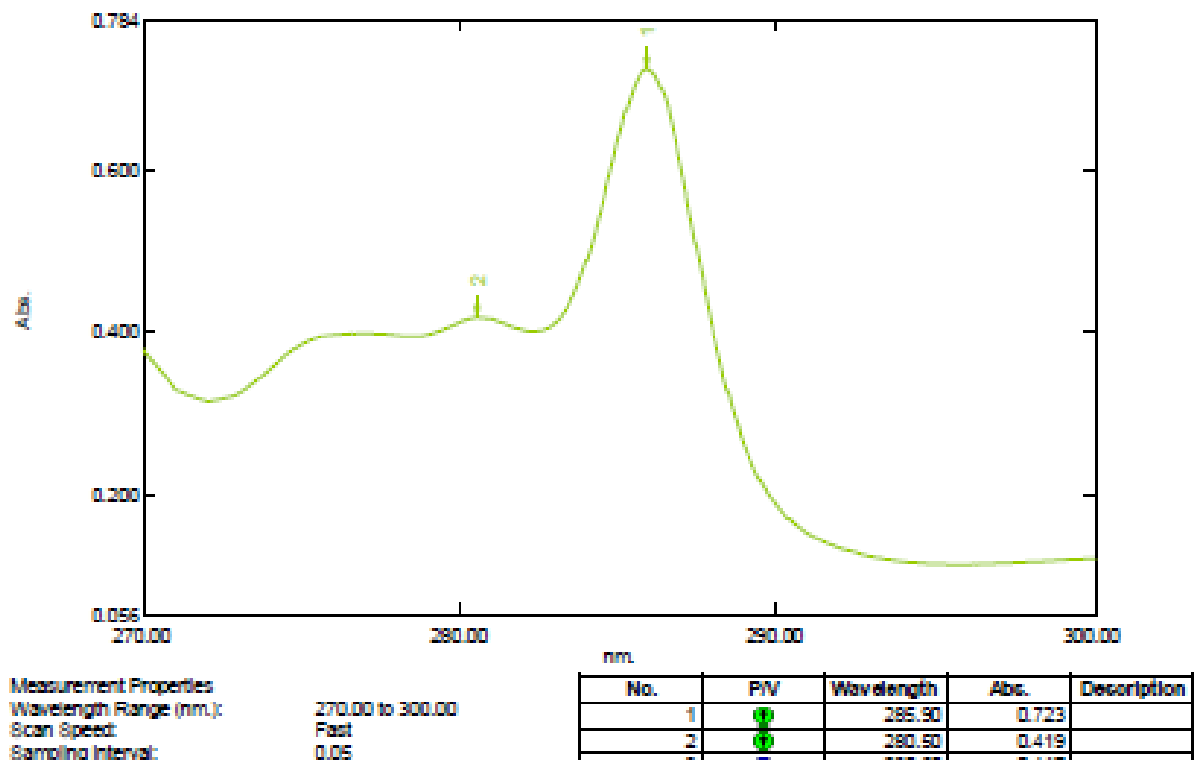

Figure S12: UV- Spectrum peak pick report of 500 ppm of DBT stranded solution. Data Set 750 - RawData

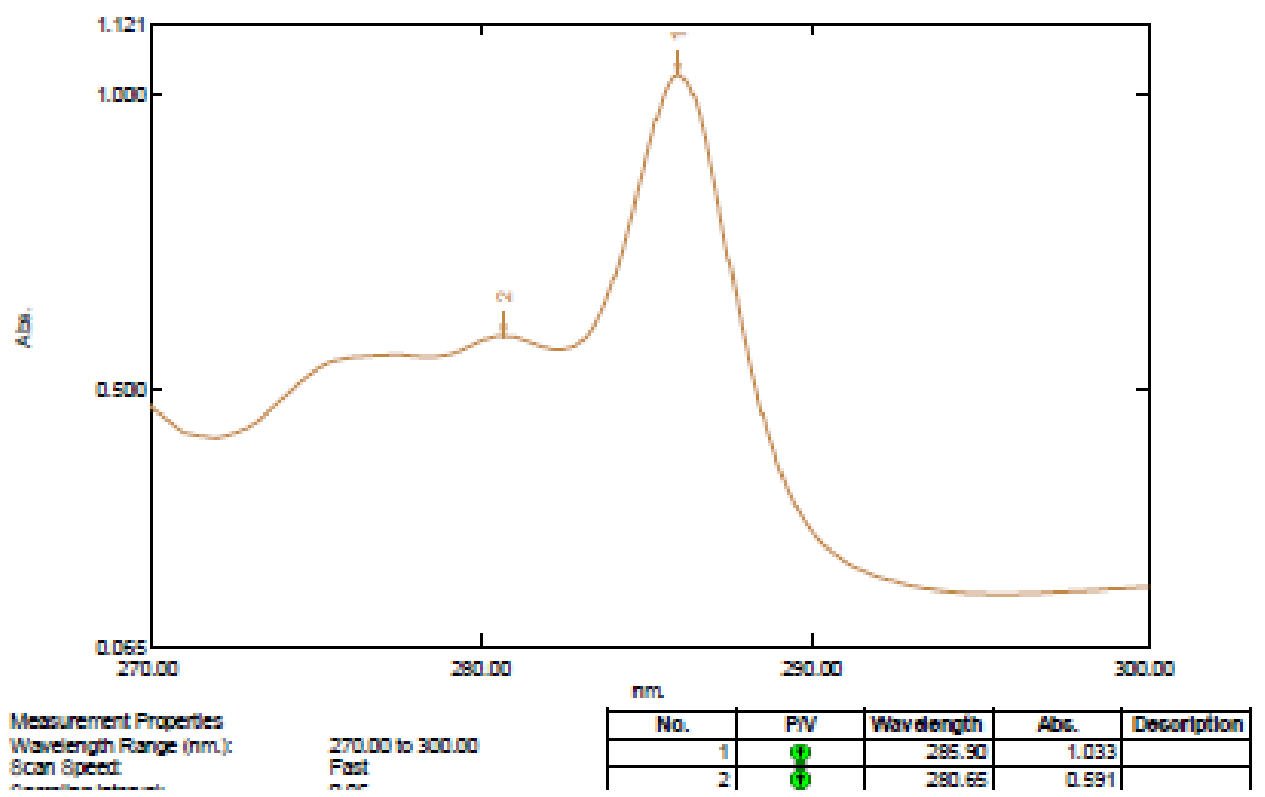

Figure S13: UV- Spectrum peak pick report of $750 \mathrm{ppm}$ of DBT stranded solution. 
Data Set: 1000 - RawData

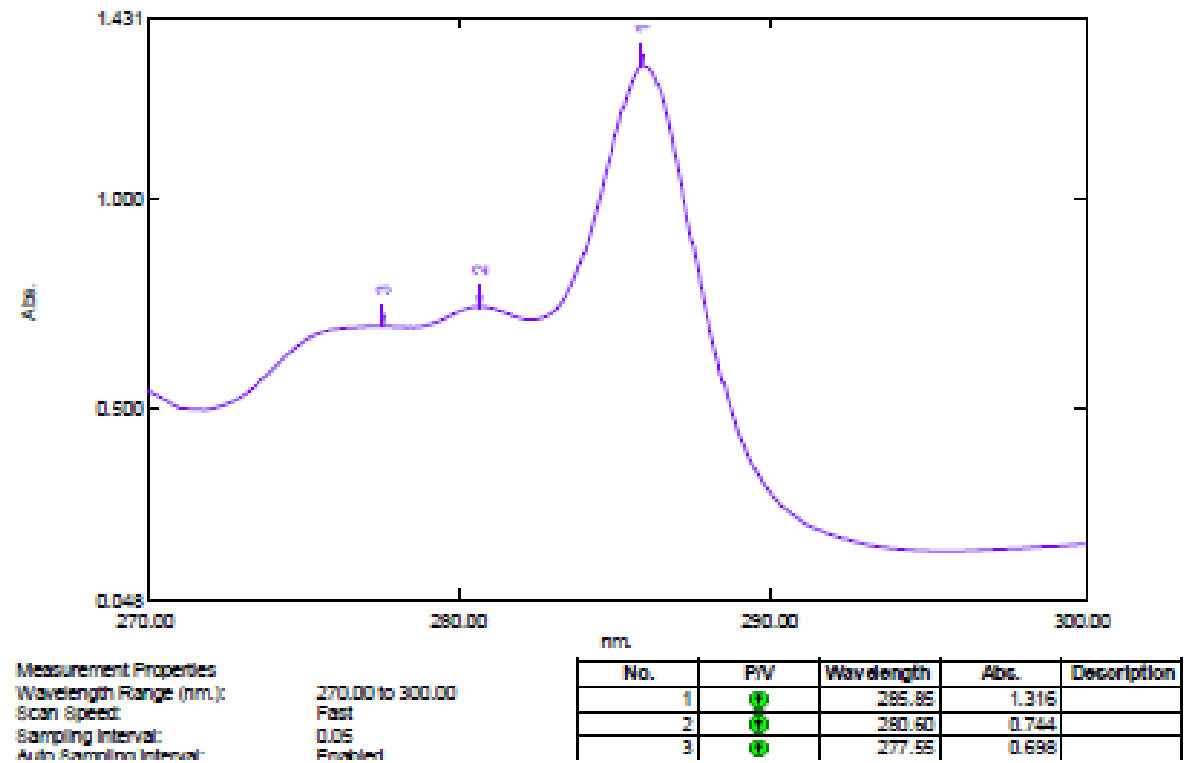

Figure S14: UV- Spectrum peak pick report of $1000 \mathrm{ppm}$ of DBT stranded solution.

Data Set: 001-1- $15 \mathrm{c}-0.05 \mathrm{~g}-30 \mathrm{~min}-$ RawData

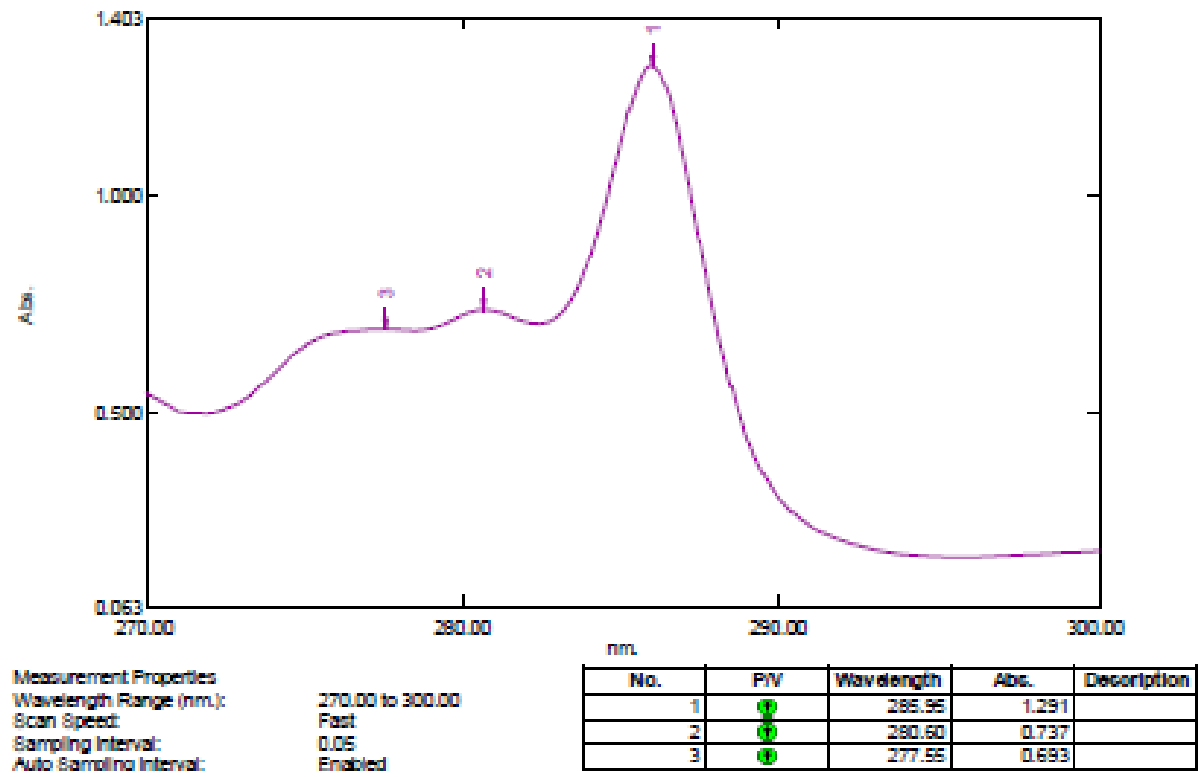

Figure S15: UV- Spectrum peak pick report of extractive desulfurization condition: extractant (1), at 15 ${ }^{\circ} \mathrm{C}$, weight of extractant $0.05 \mathrm{~g}$, time $=30 \mathrm{~min}$. 
Data Set 002-1-30c- 0.05g- $30 \mathrm{~min}$ - RawData

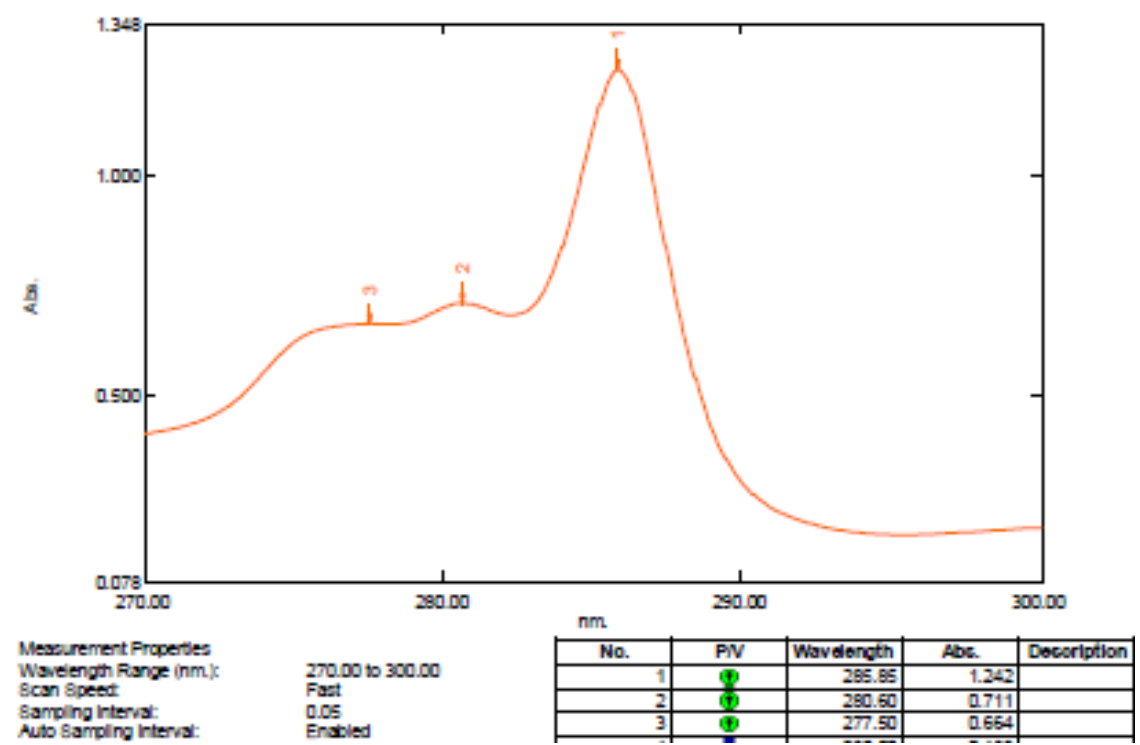

Figure S16: UV- Spectrum peak pick report of extractive desulfurization condition: extractant (1), at 30 ${ }^{\circ} \mathrm{C}$, weight of extractant $0.05 \mathrm{~g}$, time $=30 \mathrm{~min}$.

Data Set: 003- 1- 45c- 0.05g- 30 min - RawData

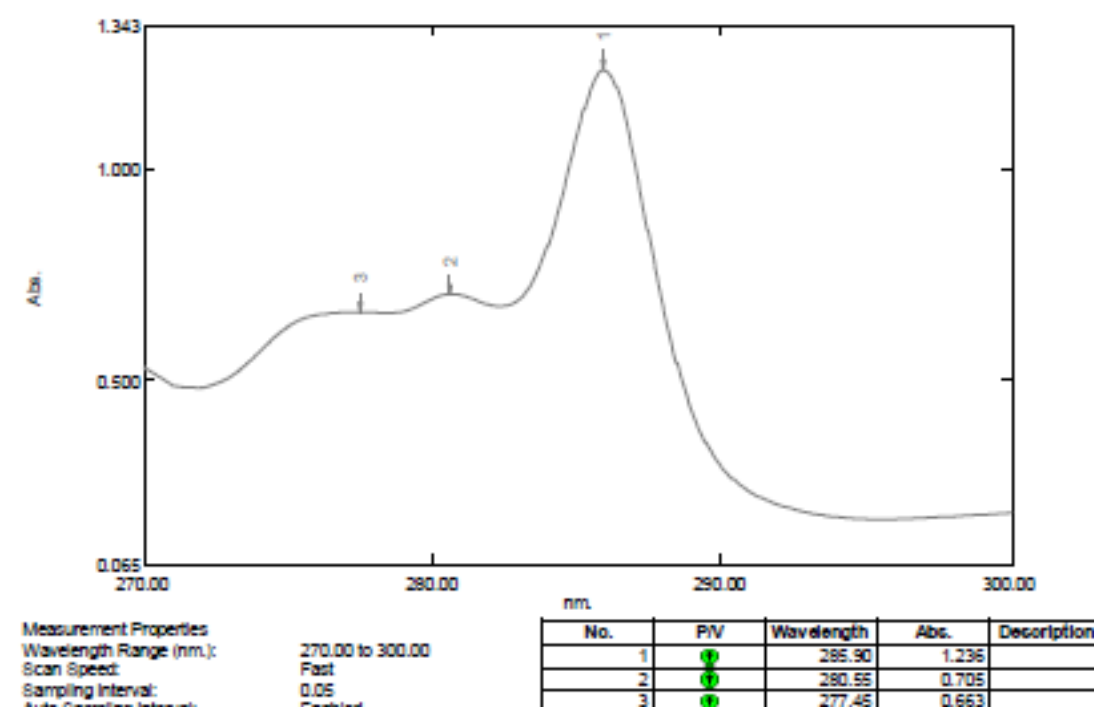

Figure S17: UV- Spectrum peak pick report of extractive desulfurization condition: extractant (1), at 45 ${ }^{\circ} \mathrm{C}$, weight of extractant $0.05 \mathrm{~g}$, time $=30 \mathrm{~min}$. 
Data Set: 004- 2- $15 \mathrm{c}-0.05 \mathrm{~g}-30 \mathrm{~min}$ - RawData

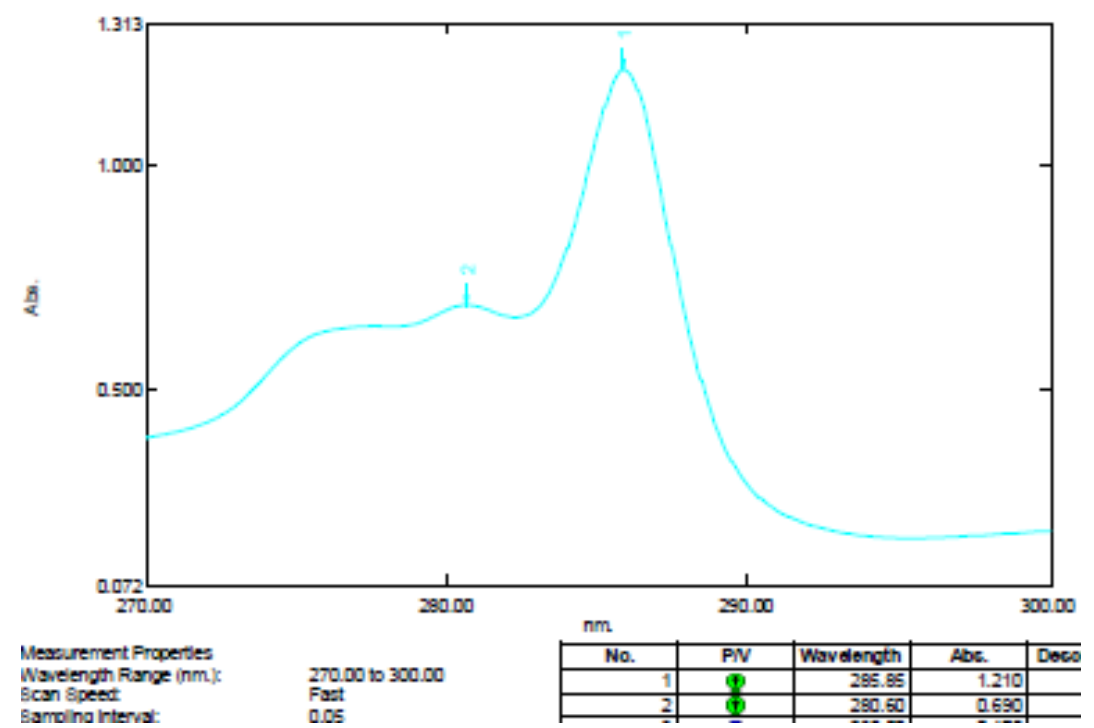

Figure S18: UV- Spectrum peak pick report of extractive desulfurization condition: extractant (2), at 15 ${ }^{\circ} \mathrm{C}$, weight of extractant $0.05 \mathrm{~g}$, time $=30 \mathrm{~min}$. Data Set 005- 2- 30c- 0.05g- $30 \mathrm{~min}$ - RawData

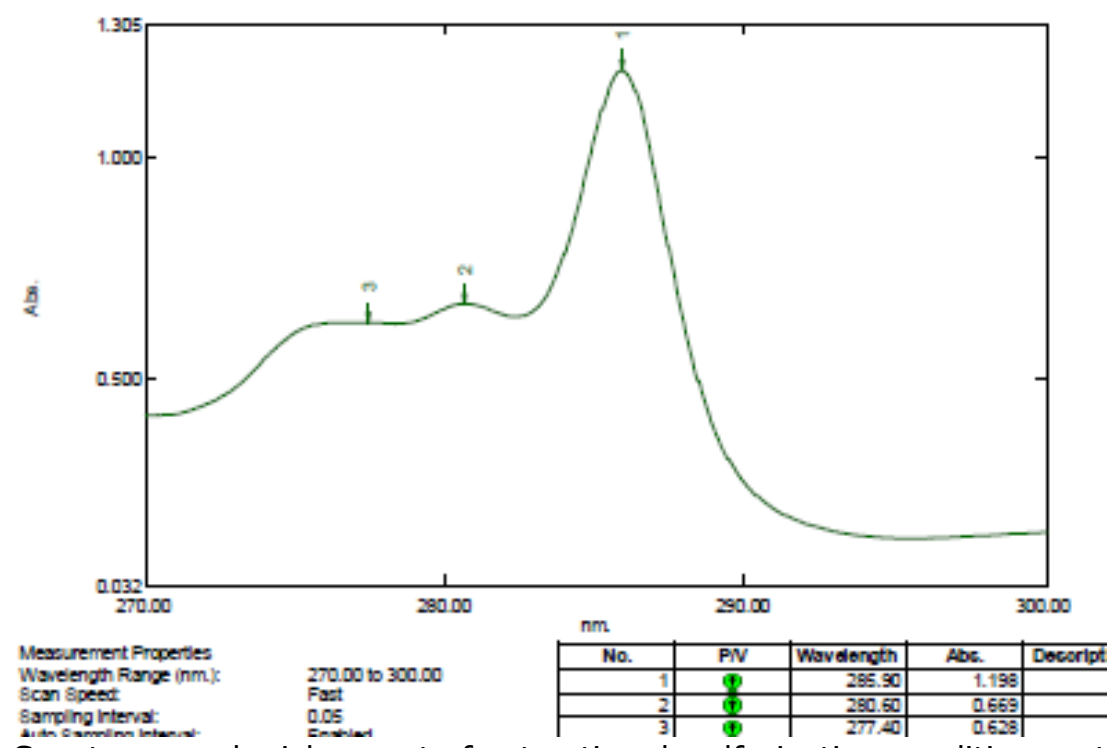

Figure S19: UV- Spectrum peak pick report of extractive desulfurization condition: extractant (2), at 30 ${ }^{\circ} \mathrm{C}$, weight of extractant $0.05 \mathrm{~g}$, time $=30 \mathrm{~min}$. 
Data Set: 006- 2- 45c- 0.05g- $30 \mathrm{~min}$ - RawData

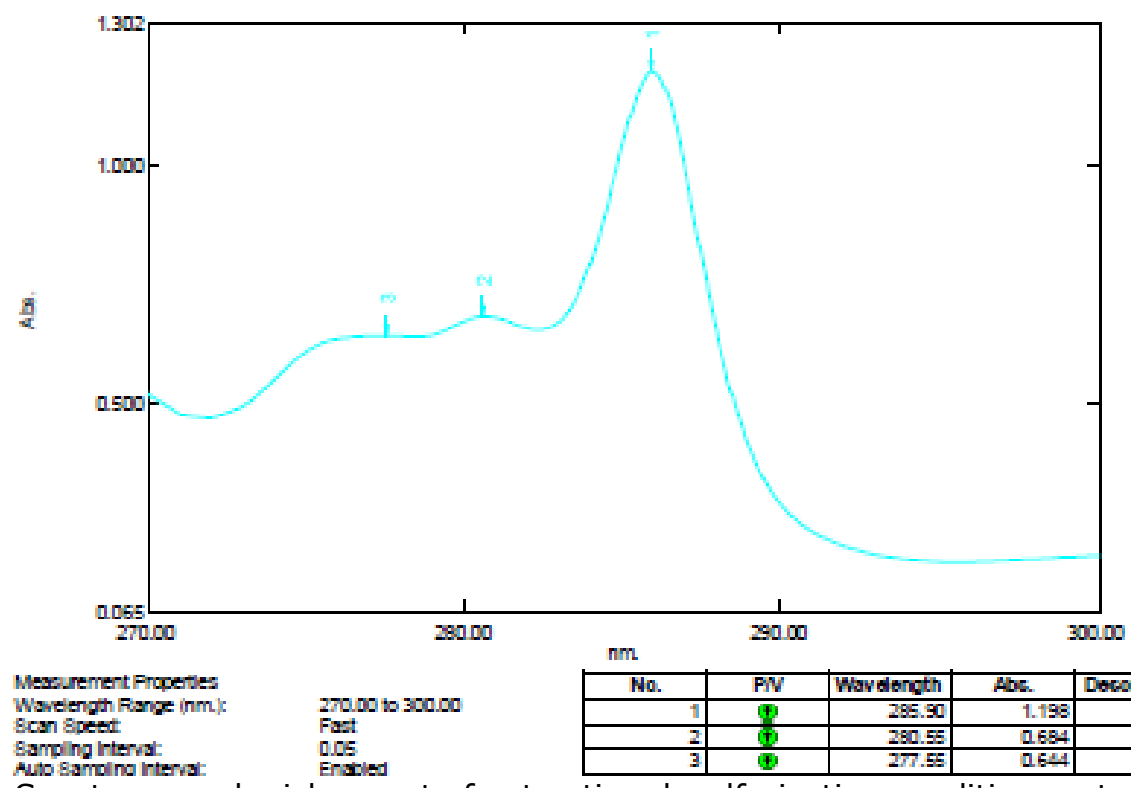

Figure S20: UV- Spectrum peak pick report of extractive desulfurization condition: extractant (2), at 45 ${ }^{\circ} \mathrm{C}$, weight of extractant $0.05 \mathrm{~g}$, time $=30 \mathrm{~min}$.

Data Set: 007- 3- 15c- 0.05g- $30 \mathrm{~min}$ - RawData

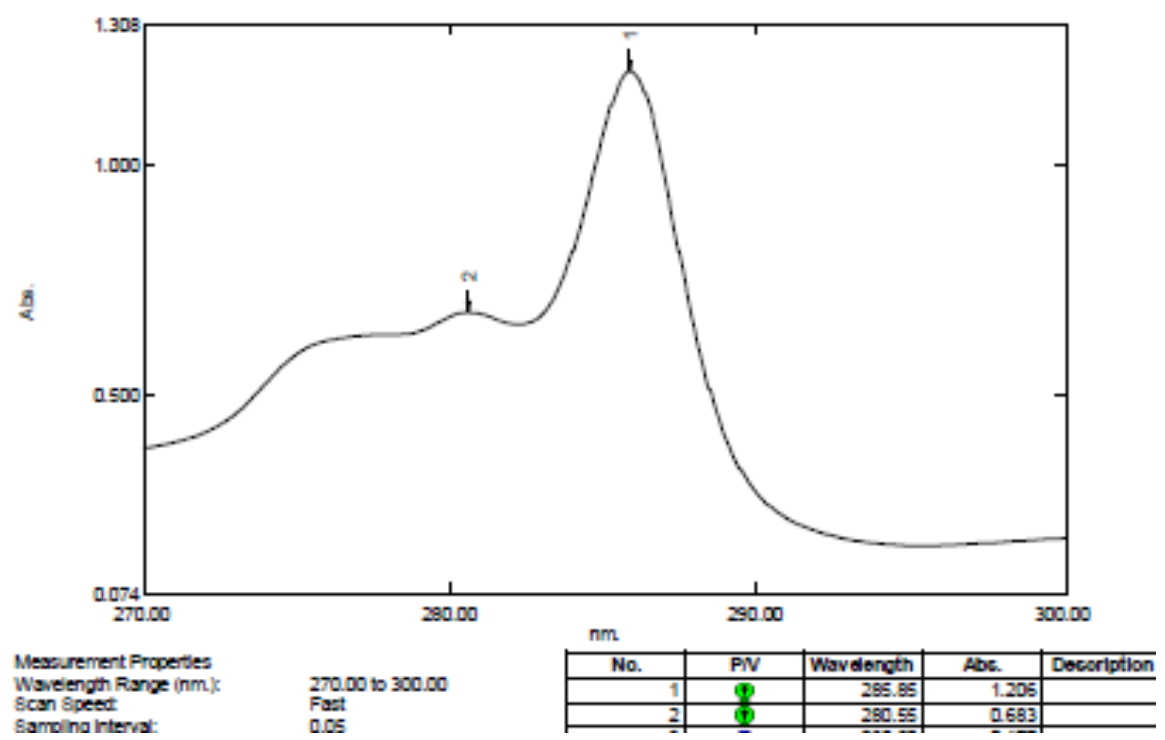

Figure S21: UV- Spectrum peak pick report of extractive desulfurization condition: extractant (3), at 15 ${ }^{\circ} \mathrm{C}$, weight of extractant $0.05 \mathrm{~g}$, time $=30 \mathrm{~min}$. 
Data Set 008- 3- 30c- 0.05g- $30 \mathrm{~min}$ - RawData

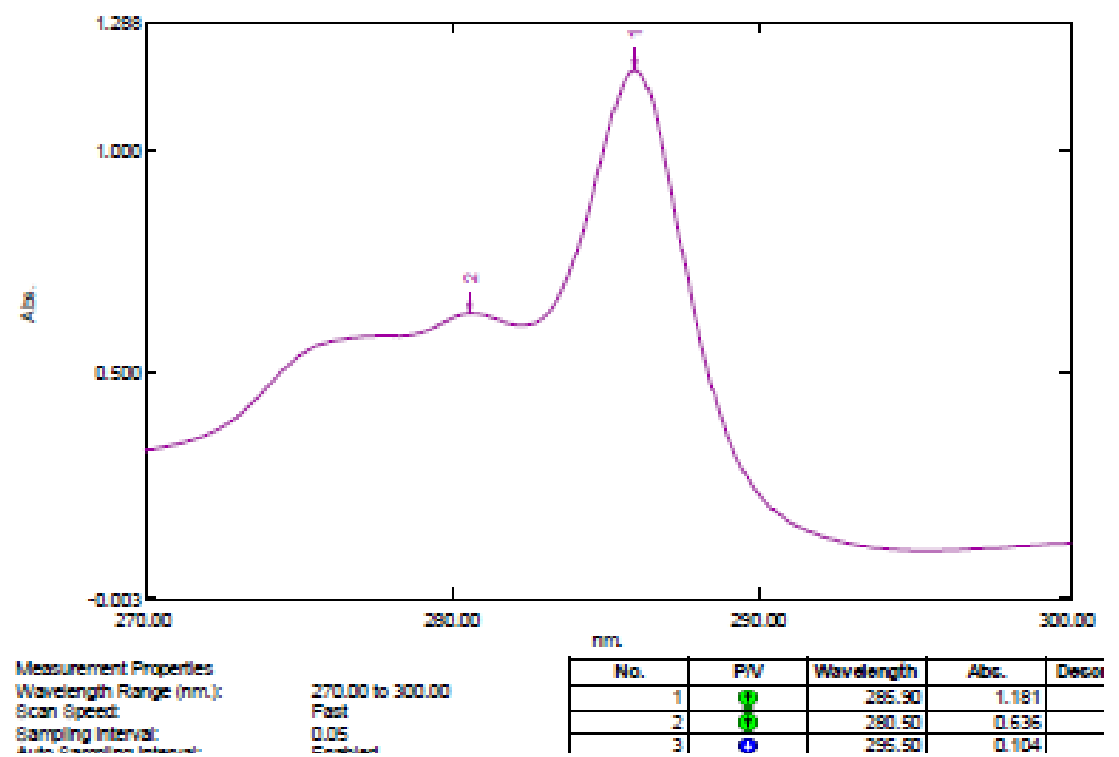

Figure S22: UV- Spectrum peak pick report of extractive desulfurization condition: Extractant (3), at 30 ${ }^{\circ} \mathrm{C}$, weight of extractant $0.05 \mathrm{~g}$, time $=30 \mathrm{~min}$.

Data Set 009-3-45c-0.05g- 30 min - RawData

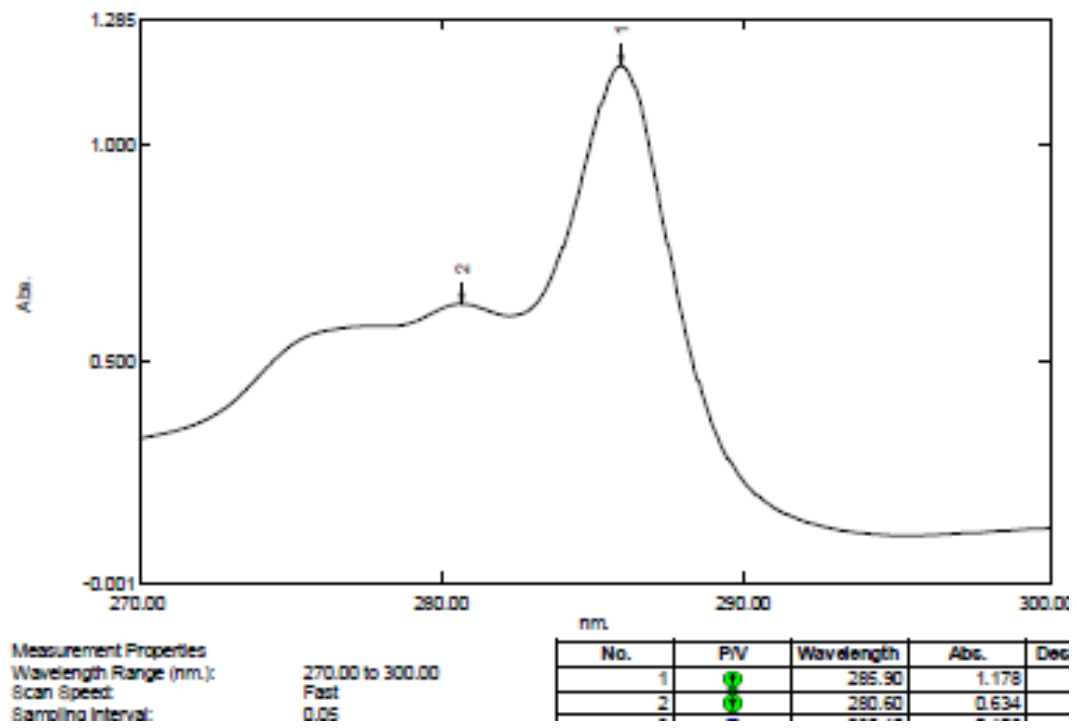

Figure 523: UV- Spectrum peak pick report of extractive desulfurization condition: extractant (3), at 45 ${ }^{\circ} \mathrm{C}$, weight of extractant $0.05 \mathrm{~g}$, time $=30 \mathrm{~min}$. 
Data Set: 010- 4- 15c-0.05g- $30 \mathrm{~min}$ - RawData

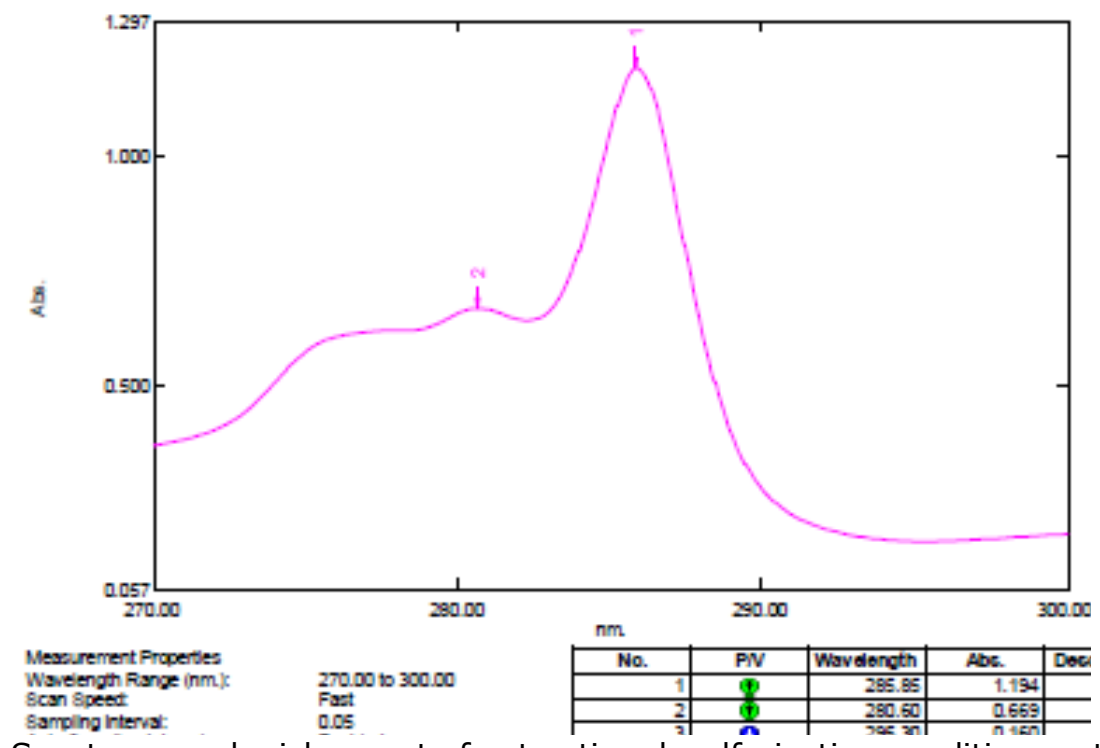

Figure 524: UV- Spectrum peak pick report of extractive desulfurization condition: extractant (4), at 15 ${ }^{\circ} \mathrm{C}$, weight of extractant $0.05 \mathrm{~g}$, time $=30 \mathrm{~min}$.

Data Set 011- 4- 30c- 0.05g- 30 min - RawData

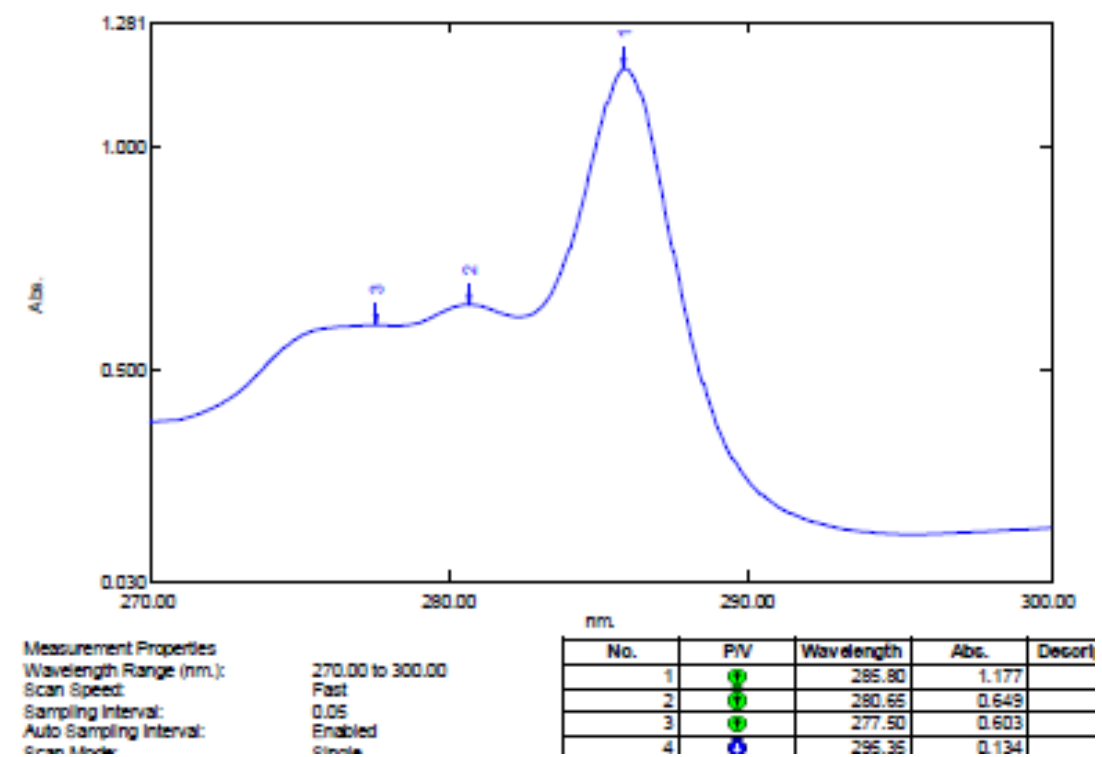

Figure S25: UV- Spectrum peak pick report of extractive desulfurization condition: extractant (4), at 30 ${ }^{\circ} \mathrm{C}$, weight of extractant $0.05 \mathrm{~g}$, time $=30 \mathrm{~min}$. 
Data Set 012- 4- 45c-0.05g- $30 \mathrm{~min}$ - RawData

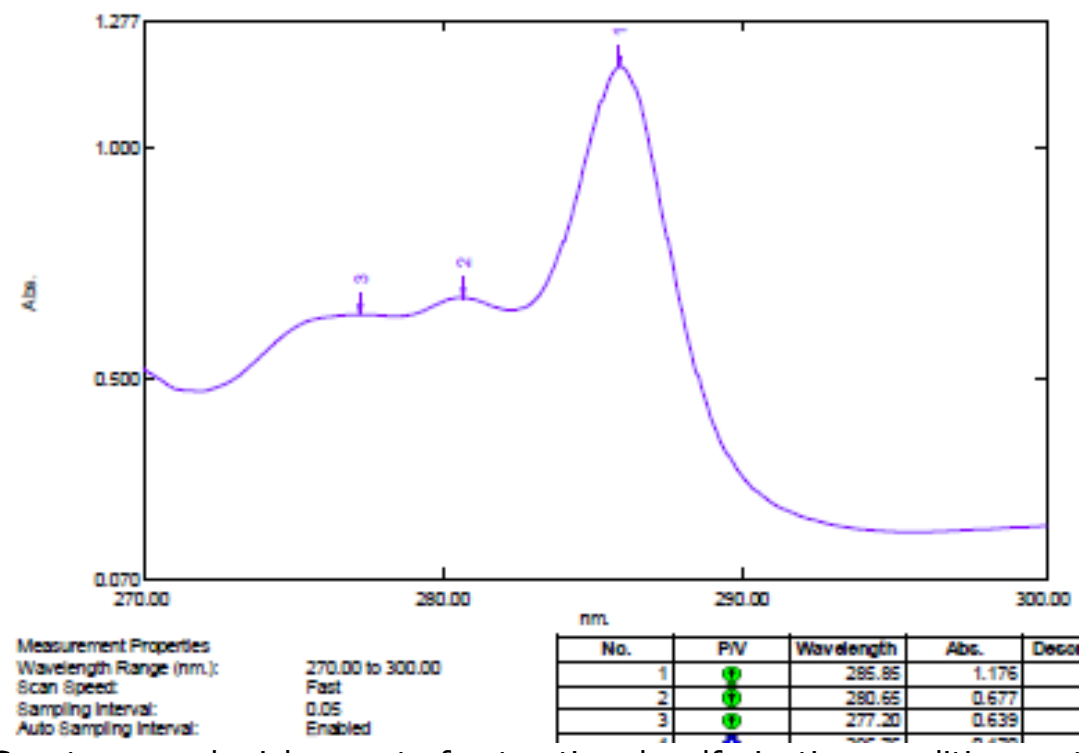

Figure S26: UV- Spectrum peak pick report of extractive desulfurization condition: extractant (4), at 45 ${ }^{\circ} \mathrm{C}$, weight of extractant $0.05 \mathrm{~g}$, time $=30 \mathrm{~min}$.

Data Set: 013 - 1- 60 min- 0.05g - 30C - RawData

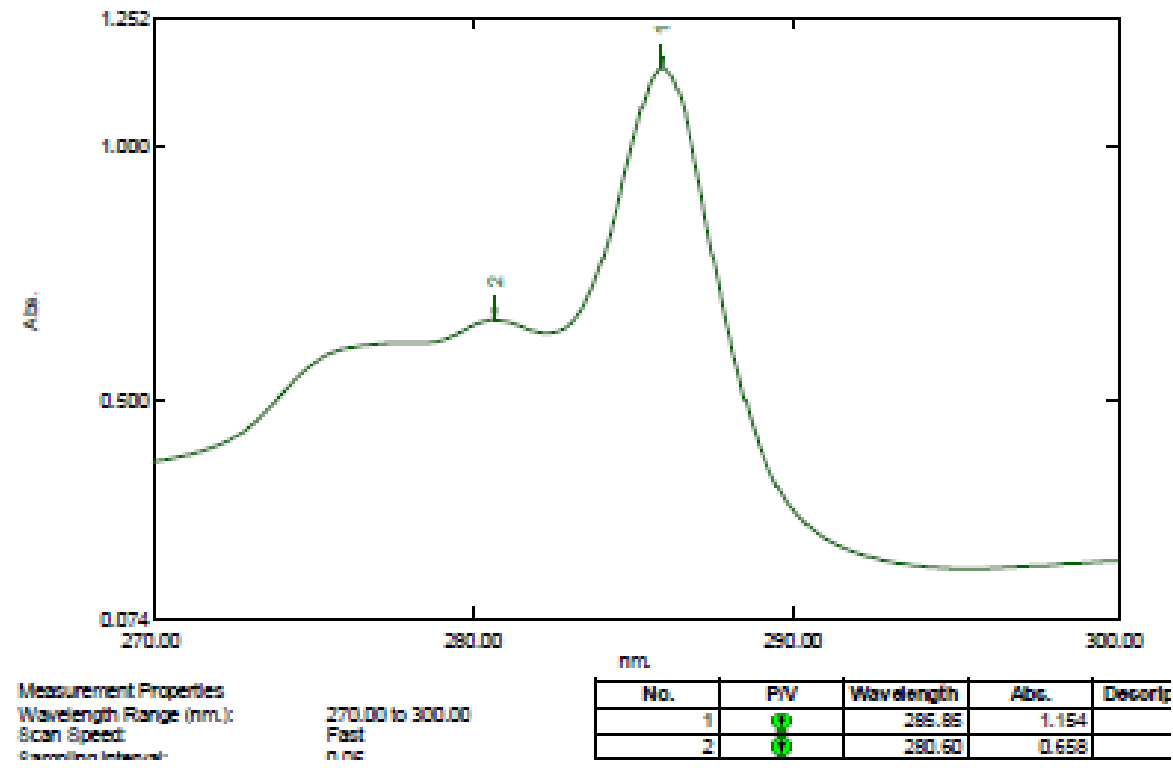

Figure S27: UV- Spectrum peak pick report of extractive desulfurization condition: extractant (1), at 30 ${ }^{\circ} \mathrm{C}$, weight of extractant $0.05 \mathrm{~g}$, time $=60 \mathrm{~min}$. 
Data Set: 014 - 1- 90 min- 0.05g - 30C - RawData

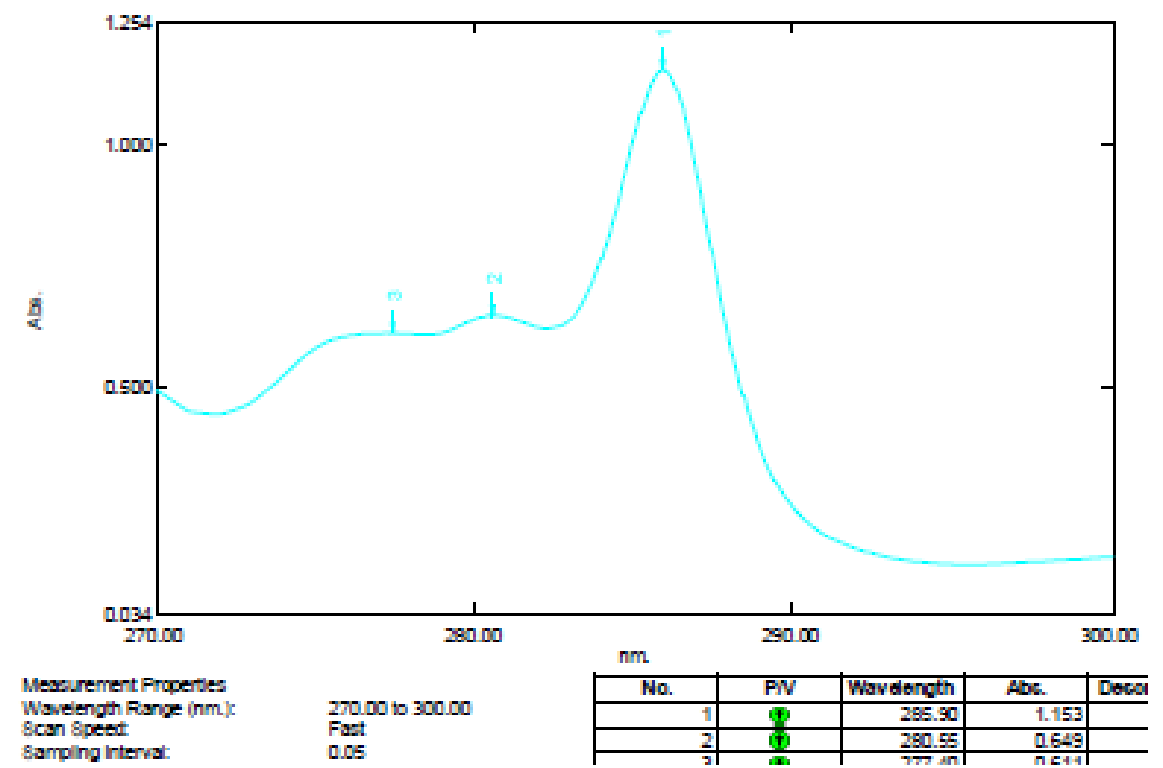

Figure S28: UV- Spectrum peak pick report of extractive desulfurization condition: extractant (1), at 30 ${ }^{\circ} \mathrm{C}$, weight of extractant $0.05 \mathrm{~g}$, time $=90 \mathrm{~min}$.

Data Set 015 - 2- 60 min- 0.05g - 30C - RawData

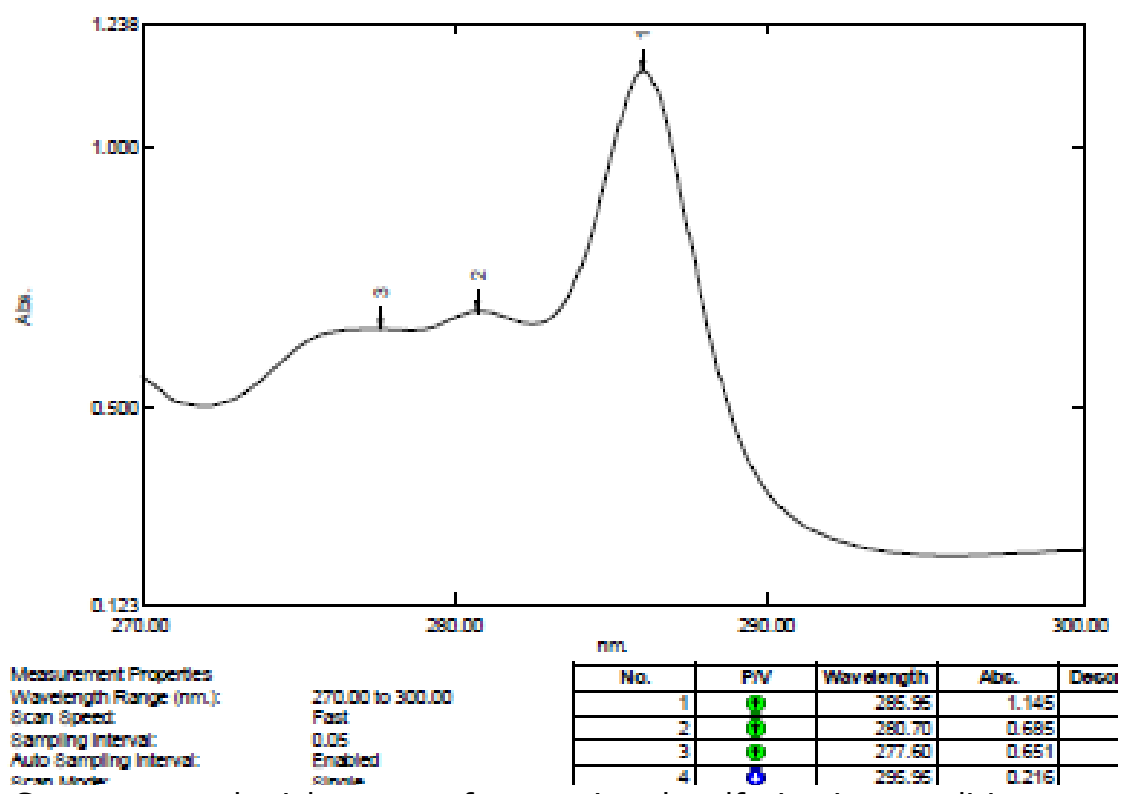

Figure S29: UV- Spectrum peak pick report of extractive desulfurization condition: extractant (2), at 30 ${ }^{\circ} \mathrm{C}$, weight of extractant $0.05 \mathrm{~g}$, time $=60 \mathrm{~min}$. 
Data Set 016 - 2- 90 min- 0.05g - 30C - RawData

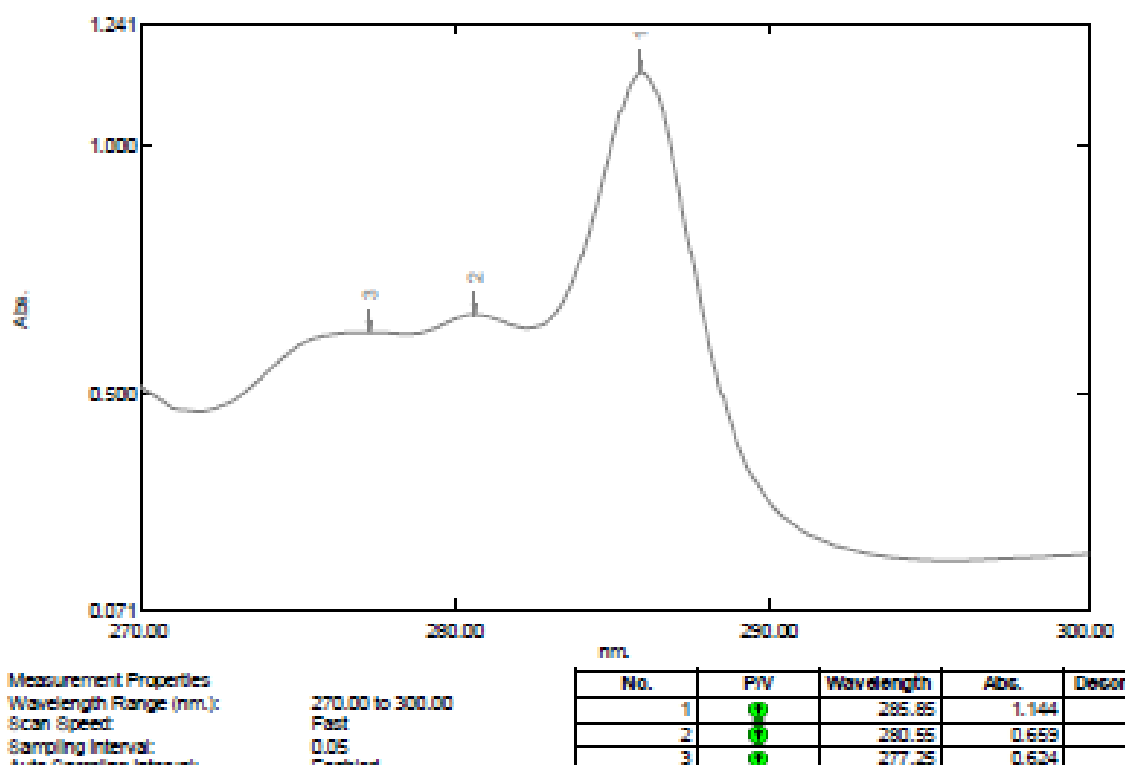

Figure S30: UV- Spectrum peak pick report of extractive desulfurization condition: extractant (2), at 30 ${ }^{\circ} \mathrm{C}$, weight of extractant $0.05 \mathrm{~g}$, time $=90 \mathrm{~min}$.

Data Set: $017-3-60$ min- 0.05g - 30C - RawData

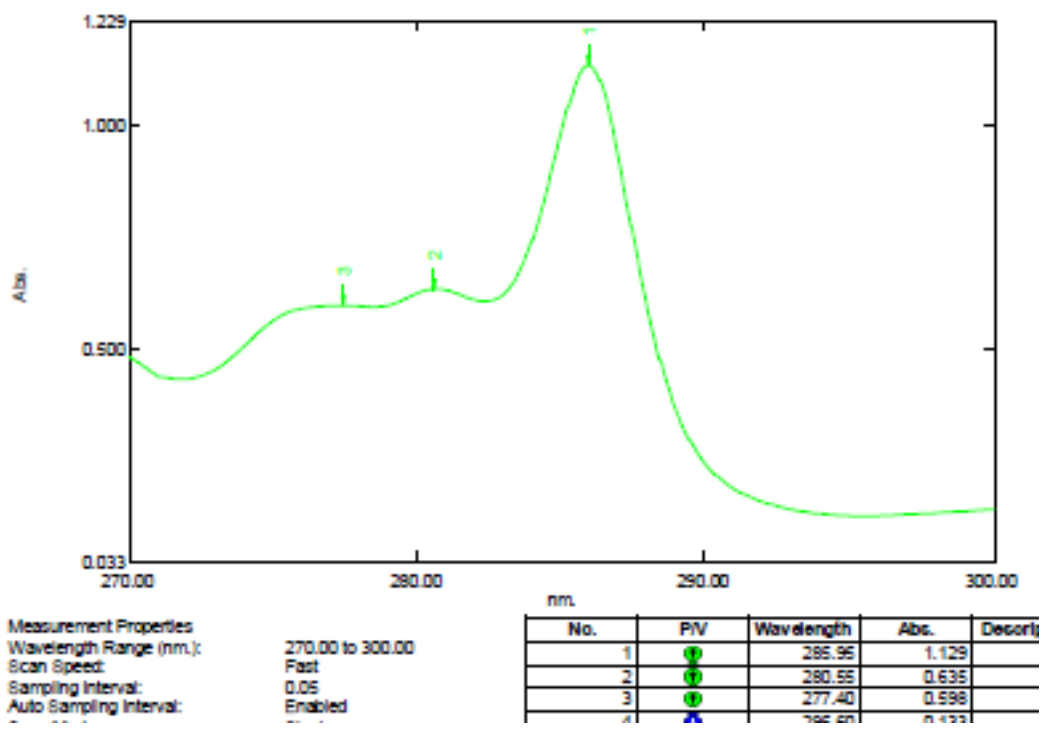

Figure S31: UV- Spectrum peak pick report of extractive desulfurization condition: extractant (3), at 30 ${ }^{\circ} \mathrm{C}$, weight of extractant $0.05 \mathrm{~g}$, time $=60 \mathrm{~min}$. 
Data Set: 018 - 3- 90 min- 0.05g - 30C - RawData

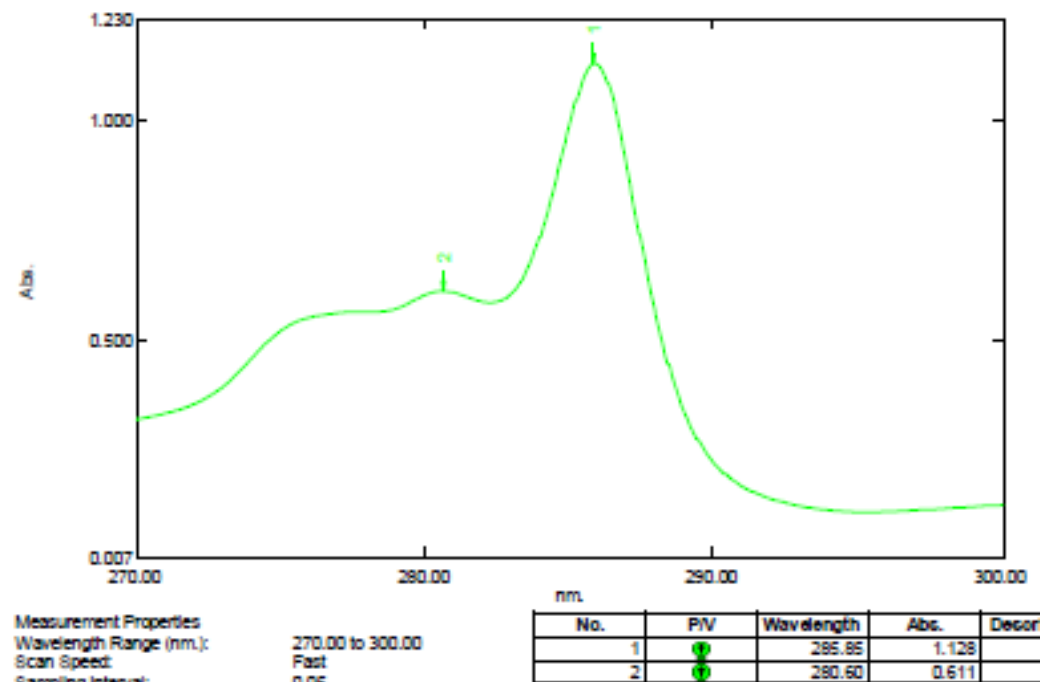

Figure S32: UV- Spectrum peak pick report of extractive desulfurization condition: extractant (3), at 30 ${ }^{\circ} \mathrm{C}$, weight of extractant $0.05 \mathrm{~g}$, time $=90 \mathrm{~min}$.

Data Set: $019-4-60$ min- 0.05g - 30C - RawData

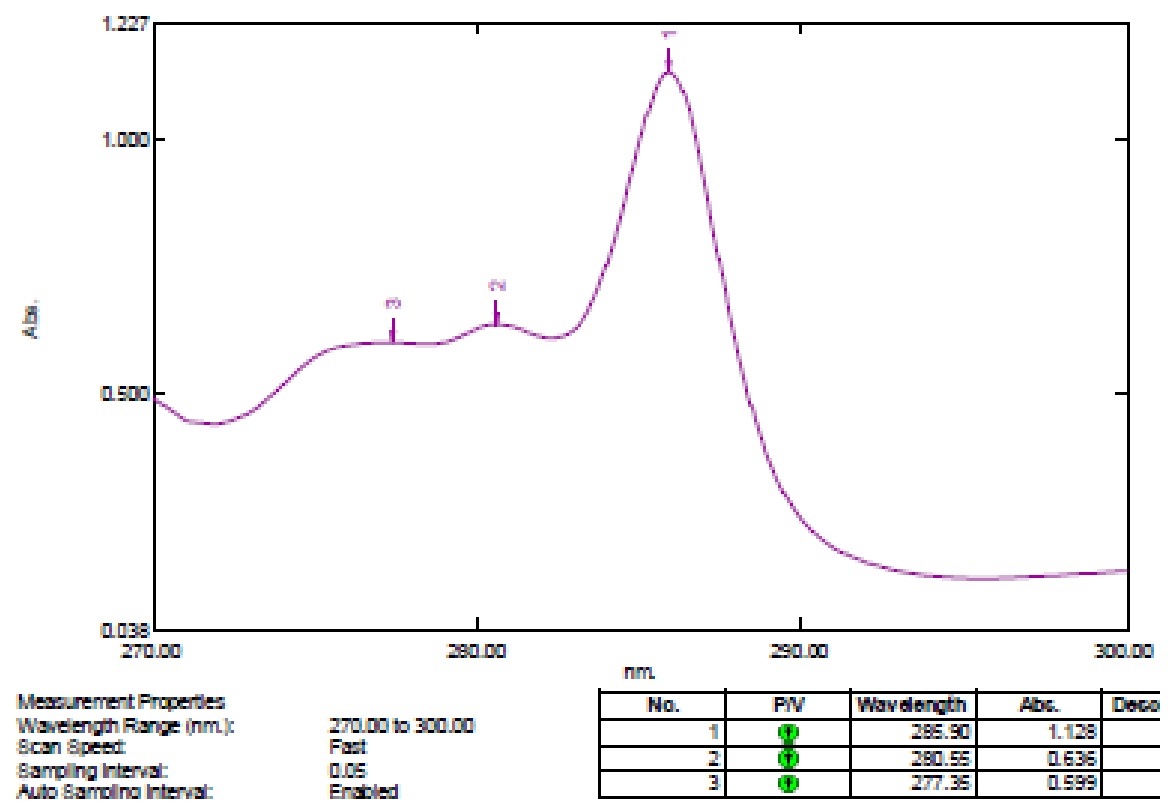

Figure S33: UV- Spectrum peak pick report of extractive desulfurization condition: extractant (4), at 30 ${ }^{\circ} \mathrm{C}$, weight of extractant $0.05 \mathrm{~g}$, time $=60 \mathrm{~min}$. 
Data Set: 020 - 4- 90 min- 0.05g - 30C - RawData

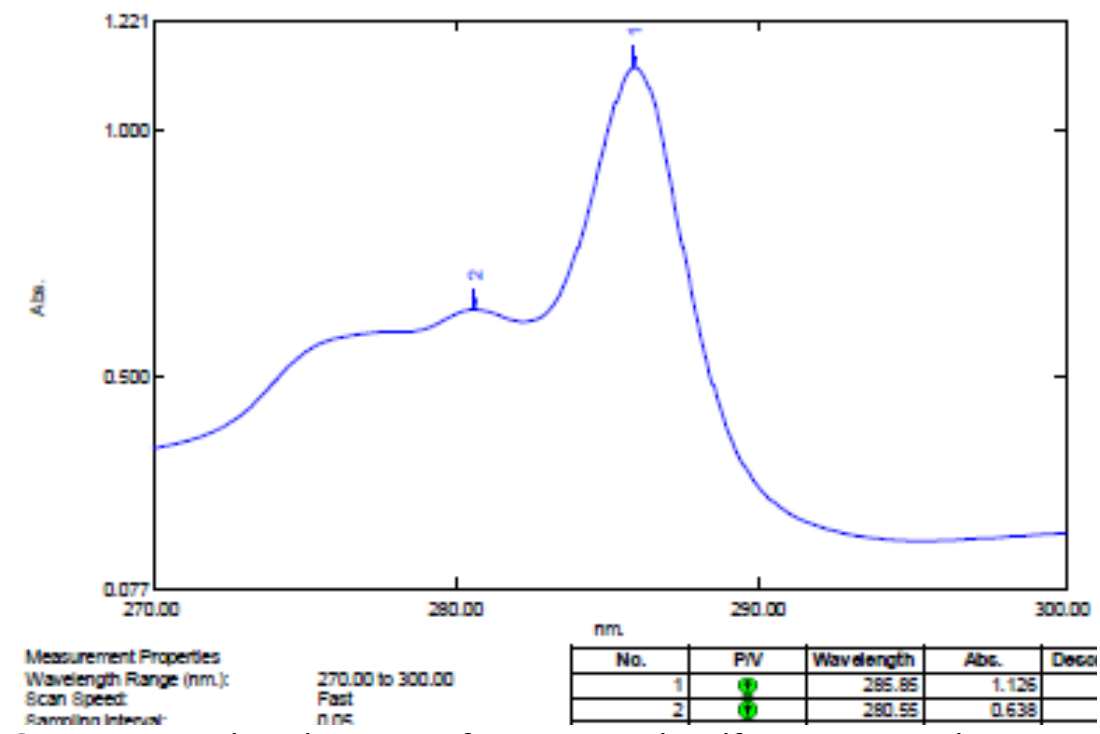

Figure S34: UV- Spectrum peak pick report of extractive desulfurization condition: extractant (4), at 30 ${ }^{\circ} \mathrm{C}$, weight of extractant $0.05 \mathrm{~g}$, time $=90 \mathrm{~min}$.

Data Set: $021-1-0.075 g-60$ min - RawData

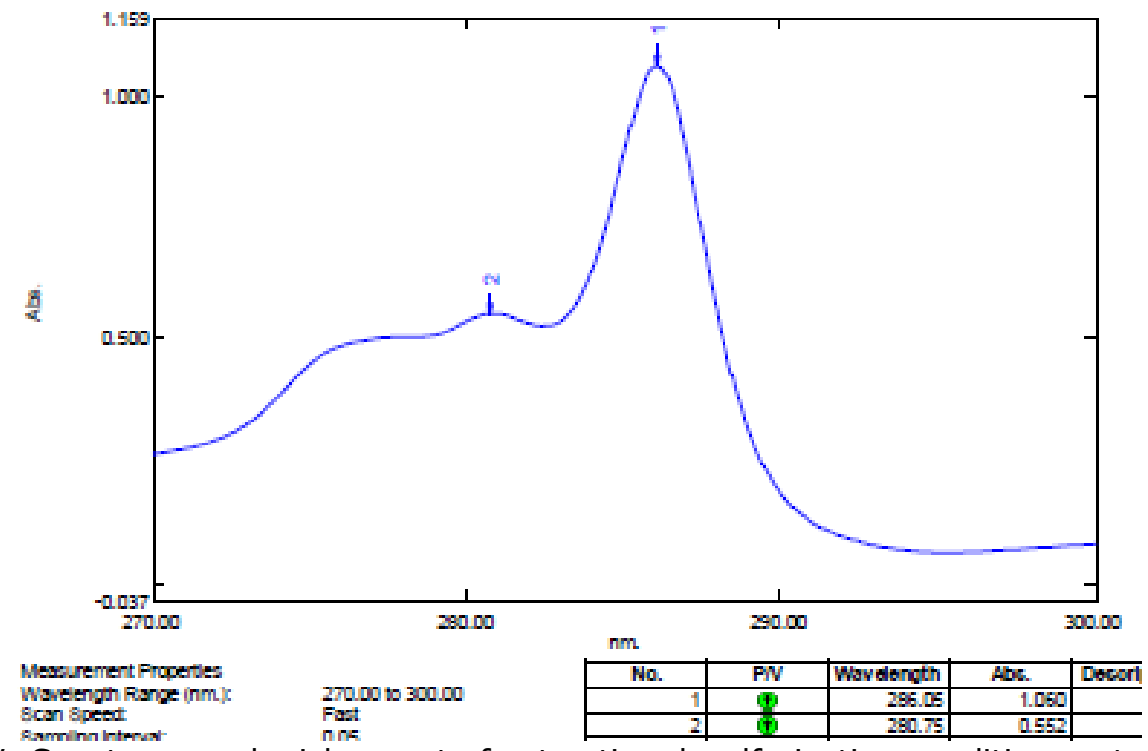

Figure S35: UV- Spectrum peak pick report of extractive desulfurization condition: extractant (1), at 30 ${ }^{\circ} \mathrm{C}$, weight of extractant $0.075 \mathrm{~g}$, time $=60 \mathrm{~min}$. 
Data Set: 022 - 1- 0.1g- 60 min - RawData

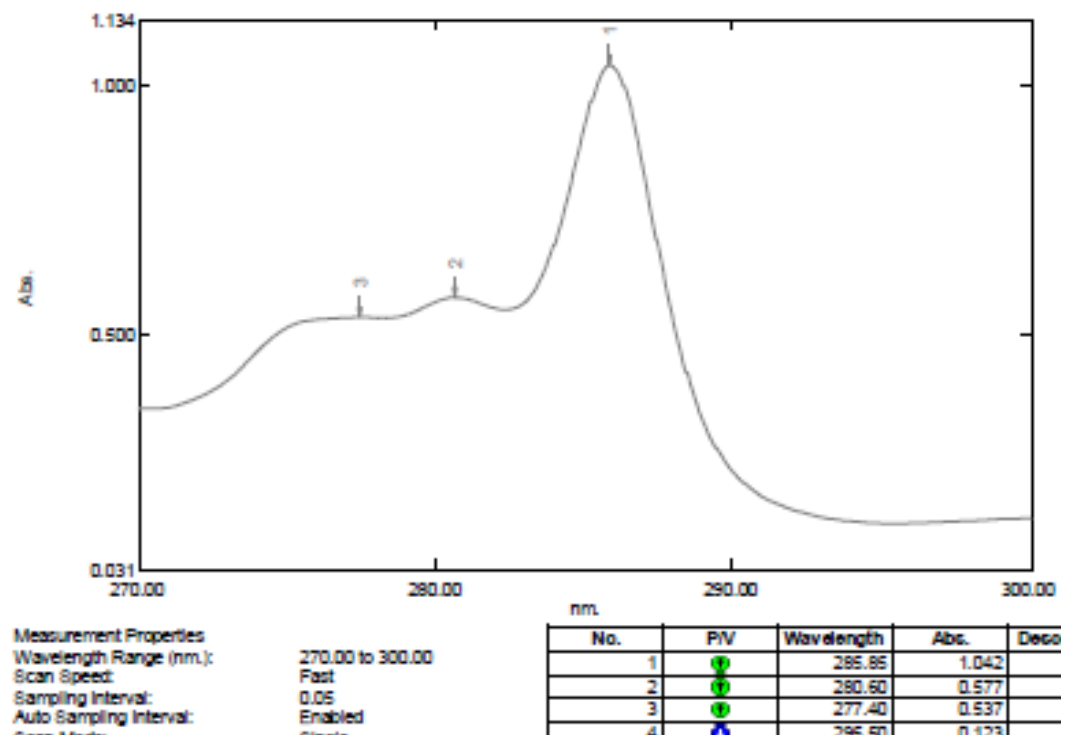

Figure S36: UV- Spectrum peak pick report of extractive desulfurization condition: extractant (1), at 30 ${ }^{\circ} \mathrm{C}$, weight of extractant $0.1 \mathrm{~g}$, time $=60 \mathrm{~min}$.

Data Set $023-2-0.075 \mathrm{~g}-60 \mathrm{~min}$ - RawData

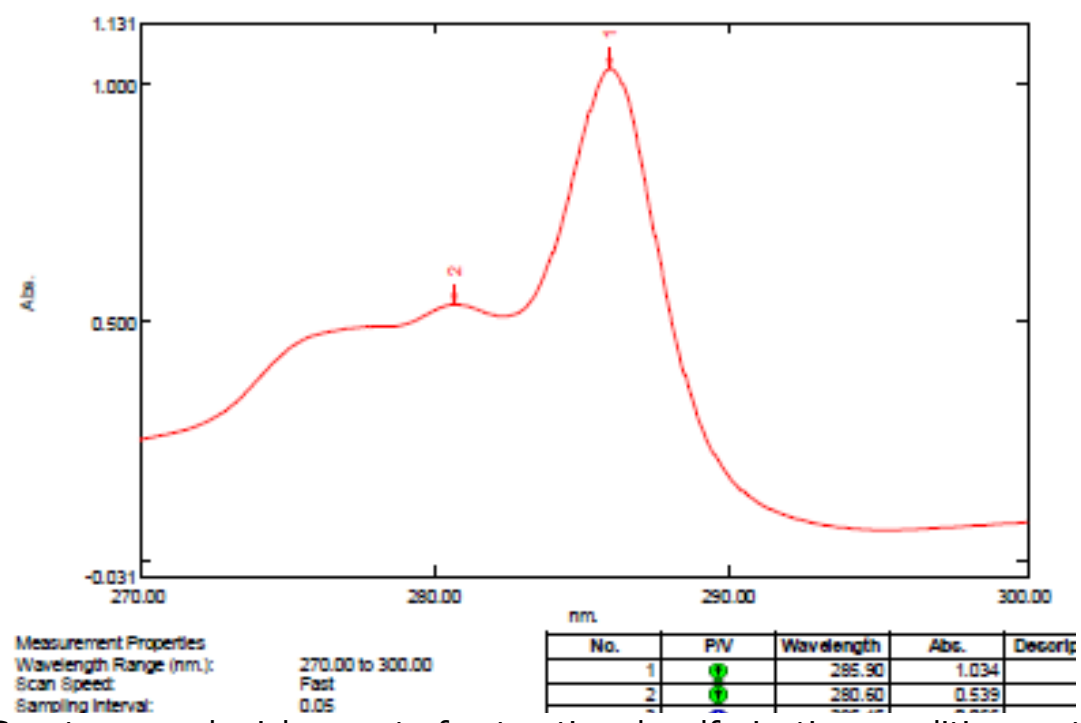

Figure S37: UV- Spectrum peak pick report of extractive desulfurization condition: extractant (2), at 30 ${ }^{\circ} \mathrm{C}$, weight of extractant $0.075 \mathrm{~g}$, time $=60 \mathrm{~min}$. 
Data Set: $024-2-0.1 \mathrm{~g}-60 \mathrm{~min}-$ RawData

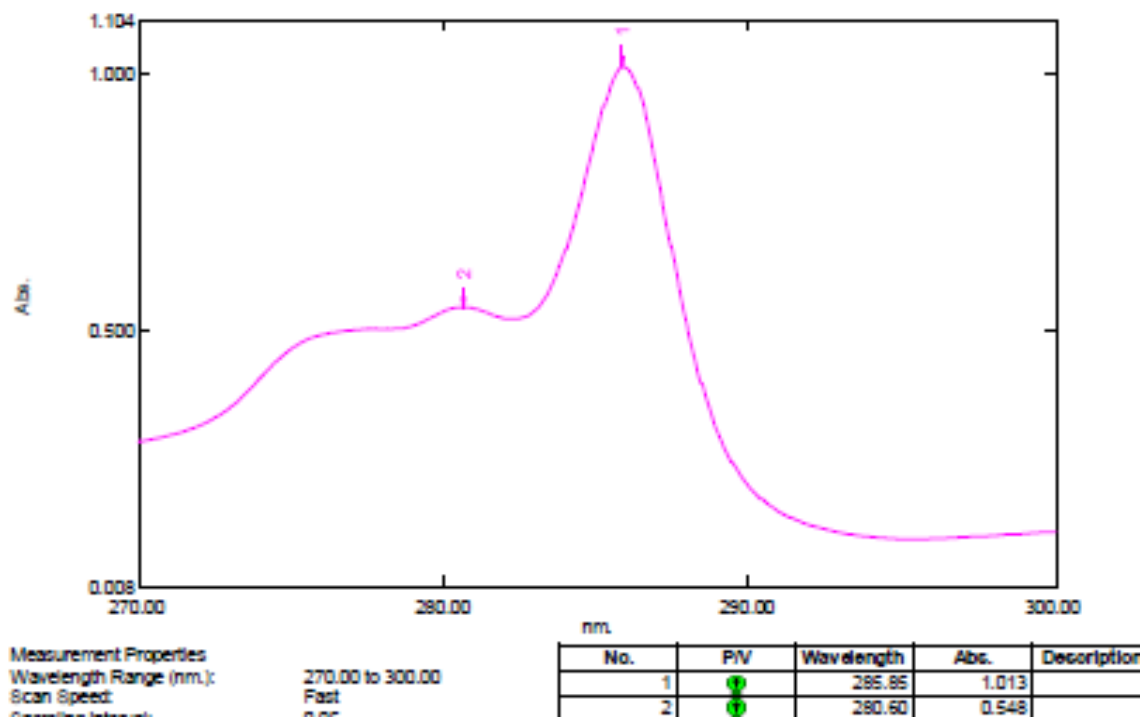

Figure S38: UV- Spectrum peak pick report of extractive desulfurization condition: extractant (2), at 30 ${ }^{\circ} \mathrm{C}$, weight of extractant $0.1 \mathrm{~g}$, time $=60 \mathrm{~min}$.

Data Set 025 -3- 0.075g - 60 min - RawData

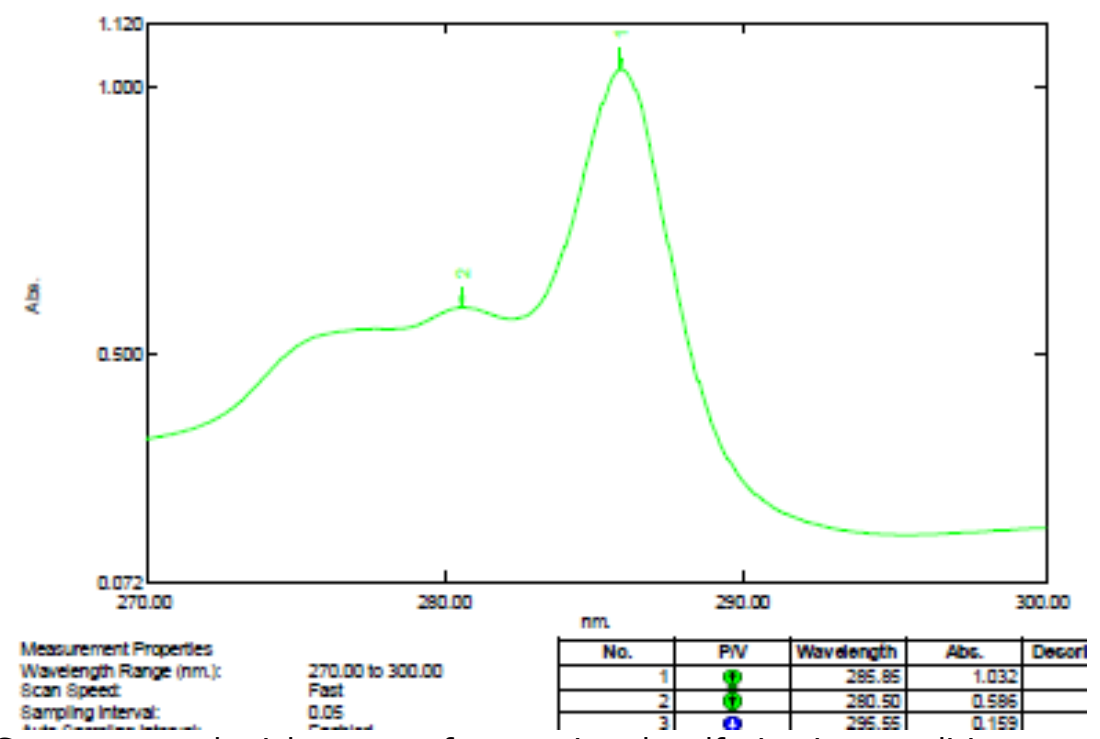

Figure S39: UV- Spectrum peak pick report of extractive desulfurization condition: extractant (3), at 30 ${ }^{\circ} \mathrm{C}$, weight of extractant $0.075 \mathrm{~g}$, time $=60 \mathrm{~min}$. 
Data Set: $026-3-0.1 \mathrm{~g}-60 \mathrm{~min}-$ RawData

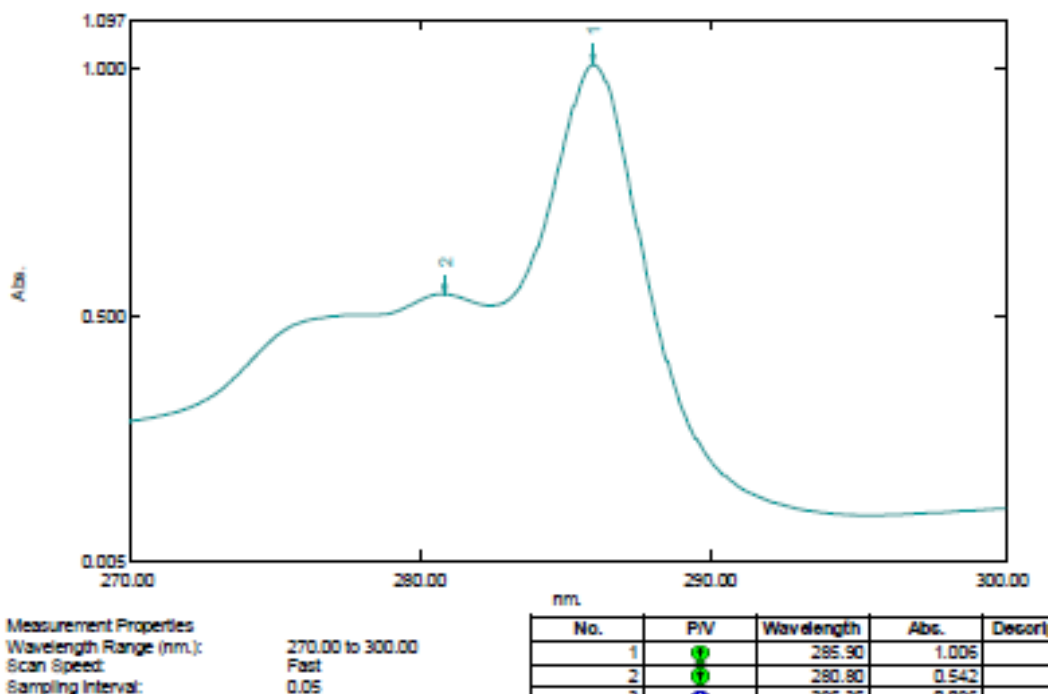

Figure S40: UV- Spectrum peak pick report of extractive desulfurization condition: extractant (3), at 30 ${ }^{\circ} \mathrm{C}$, weight of extractant $0.1 \mathrm{~g}$, time $=60 \mathrm{~min}$.

Data Set $027-4-0.075 g-60$ min - RawData

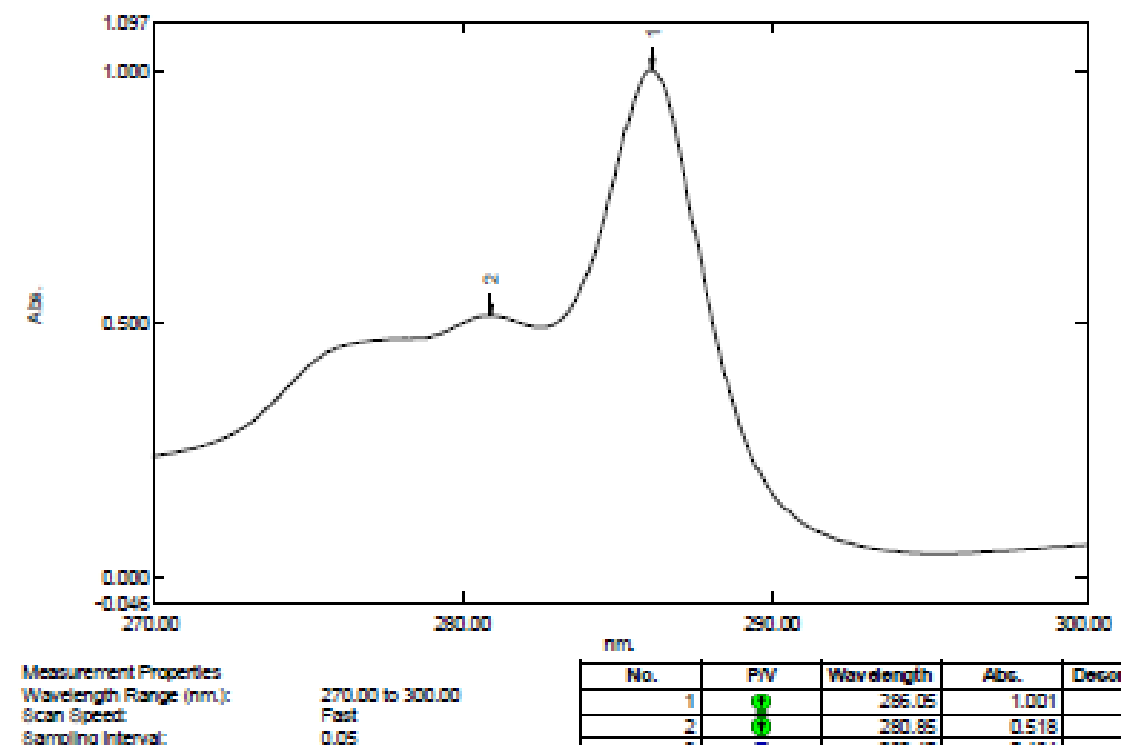

Figure S41: UV- Spectrum peak pick report of extractive desulfurization condition: extractant (4), at 30 ${ }^{\circ} \mathrm{C}$, weight of extractant $0.075 \mathrm{~g}$, time $=60 \mathrm{~min}$. 
Data Set: $028-4-0.1 \mathrm{~g}-60 \mathrm{~min}$ - RawData

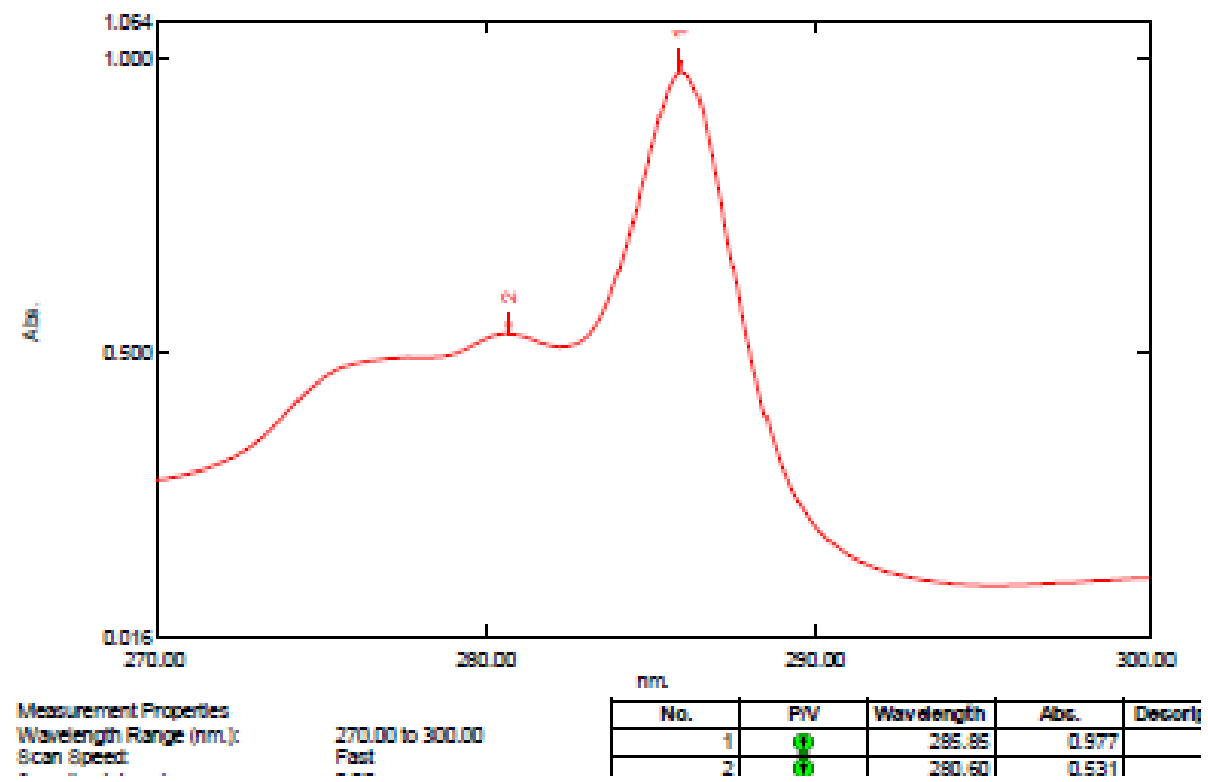

Figure S42: UV-Spectrum peak pičk report of extractive desulfurization condition: extractant (4), at 30 ${ }^{\circ} \mathrm{C}$, weight of extractant $0.1 \mathrm{~g}$, time $=60 \mathrm{~min}$. 
